\title{
Supporting Children's Understanding of Volume Measurement and Ability to Solve Volume Problems: Teaching and Learning
}

\author{
Hsin-Mei E. Huang ${ }^{1 *}$, Hsin-Yueh Wu ${ }^{1}$ \\ ${ }^{1}$ University of Taipei, Taiwan, REPUBLIC OF CHINA \\ Received 19 April 2019 - Accepted 21 May 2019
}

\begin{abstract}
This research examined the effects of two instructional treatments on training performance in solid volume measurement and potential effects on solving capacity and displaced volume problems by two related studies. Fifty-three fifth-graders from a public elementary school in Taipei, Taiwan, participated. In the Phase 1 study, the children $(n=27)$ who received a curriculum that integrated geometric knowledge with concepts of volume measurement (GKVM) showed greater competence in solving problems than did those $(n=26)$ who received a curriculum that emphasized measurement procedures and volume calculation (VM). In the subsequent Phase 2 , the same two groups received identical instruction in capacity, and the group that received the GKVM curriculum showed better problem-solving performance than did the other group. The one-on-one interview data showed that the children's prior knowledge of solid volume measurement had a critical influence on the solving of advanced problems involving capacity and volume displacement concepts.
\end{abstract}

Keywords: geometric knowledge, problem solving, solid volume, volume measurement, water volume

\section{INTRODUCTION}

Concepts of volume measurement and their related concepts such as capacity and volume displacement are important subject matters in school mathematics (Ministry of Education [in Taiwan], 2010; National Council of Teachers of Mathematics [NCTM], 2006). Despite the importance of volume measurement, elementary-school children frequently struggle with solving volume problems, such as seeing the structure of 3-dimensional (3D) objects in terms of units of measure and integrating information of three linear dimensions of the objects when reasoning about volume formulae (Battista \& Clements, 1996, 1998; Vasilyeva et al., 2013). Children's difficulties can also be found in solving displaced volume problems (Bell, Hughes, \& Rogers, 1975; Dickson, Brown, \& Gibson, 1984). Accordingly, empirical studies on providing effective instructional interventions for supporting children's construction of a comprehensive understanding of volume measurement become significantly important.

A growing body of research has suggested that demonstrating two-dimensional (2D) or 3D shapes in different orientations and their spatial relations via static and dynamic representations through computer technologies may assist students in constructing geometric knowledge (Battista, 2007; Guven, 2012). Moreover, previous studies of Hsieh and Haung (2013) and Huang (2015a) found that a curriculum integrating geometric knowledge with concepts of volume measurement (GKVM), which uses dynamic software to improve students' acquisition of the properties of 2D and 3D shapes and the related procedures required for the conceptual understanding involved in the measurement of solid volumes, promotes fourth- and fifth-graders' understanding of solid volume measurement. Whether and to what extent the instructional treatment may facilitate children's application of volume measurement skills obtained to the later solving of advanced volume problems (e.g., capacity and displaced volume) remain unclear. The ability to solve capacity and displaced volume problems is critical for successful performance in mathematics and science reasoning (Vasilyeva et al., 2013). It is important to go beyond documenting children's learning of solid volume to explore how children see the relationships between solid and water volume.

(C) 2019 by the authors; licensee Modestum Ltd., UK. This article is an open access article distributed under the terms and conditions of the Creative Commons Attribution License (http://creativecommons.org/licenses/by/4.0/).

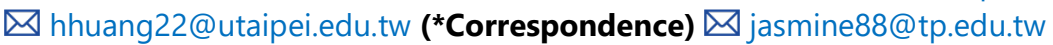




\section{Contribution of this paper to the literature}

- The developed computer-based curriculum that integrated geometric knowledge with concepts of volume measurement by using the guided instructional approach provides efficacy to students' understanding of measurement knowledge involving solid volume, water volume, and displacement volume.

- The effective curriculum facilitated students' understanding of volume formulae and reasoning in solving volume problems that required conceptual understanding of volume measurement.

- The results demonstrate that children's prior knowledge of solid volume measurement had a critical influence on their ability to solve advanced problems involving capacity and volume displacement concepts.

The current study aimed to support the development of children's volume measurement concepts by examining two aspects: (1) the effectiveness of two computer-based instructional treatments (the GKVM curriculum vs. the VM curriculum) on training performance of solid volume measurement, and (2) the potential effectiveness of these two instructional treatments on later capacity and displaced volume performance.

\section{THEORETICAL FRAMEWORK}

\section{Essential Knowledge for the Understanding of Volume Measurement}

Volume measurement includes measuring the volume of the space occupied by a 3D object (exterior volume), and the amount of liquid or other pourable material it can hold (interior volume; capacity of a container) (Dickson et al., 1984; Van de Walle, Karp, \& Bay-Williams, 2012). The terminology used to convey the notion of volume differs according to the types of materials such as solids and water.

For cognitive construction of the structure of 3D cube arrays, Battista and Clements $(1996,1998)$ and Lehrer (2003) have suggested that when children conceptualize and enumerate the cubes in the structure of 3D arrays, they should integrate information about different spatial dimensions of the object such as perceiving the proper organization of faces representing the same cubes and understand that these cubes describe an orthogonal relationship among faces that specifies exactly how they are joined together. Thus, the development of a mental construct of a 3D cube array enables children to see such arrays as representations of composite units of cubes and to perceive them as space filling via an understanding of layers, which can be vertical or horizontal (Battista \& Clements, 1996; 1998; Vasileva et al., 2013).

Furthermore, knowing how to count the number of cubes in a layer and multiplying the quantity by the number of layers needed to completely fill in the solid rectangle attribute to procedural knowledge of volume measurement (Battista, 2007; Vasileva et al., 2013). All of these examples of conceptual and procedural knowledge of solid volume measurement, which form the core of understanding of the volume formula for rectangular solids $(\mathrm{volume}[\mathrm{v}]=$ length [1] $\times$ width $[\mathrm{w}] \times$ height $[\mathrm{h}]$, hereafter referred to as the volume formula), are closely related to geometric knowledge and 3D spatial reasoning.

It is noteworthy that counting unit cubes and using the volume formula does not necessarily mean an understanding of the conceptual basis of volume measurement. The findings provided by Vasileva et al.'s (2013) and Huang's (2015a) studies indicated that some fifth-grade students used the volume formula without an understanding of the conceptual underpinnings of the formula. Accordingly, to succeed in the measurement of cuboid volume requires a conceptual understanding integrating 3D geometric knowledge and the unit structure of an array and algorithms, which links the layer structure to the volume formula.

\section{The Conventional Curriculum and Instruction in Volume Measurement}

Previous studies (Battista \& Clements, 1998; Tan, 1998) have indicated that the traditional curriculum offered for school mathematics cannot adequately develop children's reasoning about measureable geometric quantities. Some previous studies on the conventional approach for teaching volume measurement (Huang, 2015b; Tan, 1998) have indicated that teachers are inclined to pay more attention to students' unit calculations, measuring operations, and application of formulae while neglecting discussion of the relationship between numerical calculation of a measure and its conceptual structure.

In line with these studies on volume measurement instruction, Huang (2015b) found evidence to suggest that the connections among the attributes of interior and exterior volume measurement and the structure of 3D arrays of rectangular solid are rarely addressed in volume lessons. The neglect of in-depth explorations involving spacefilling and layer structure while teaching volume measurement may cause children's difficulties in solving volume problems (Battista \& Clements, 1998; Vasilyeva et al., 2013). 
Children's common difficulties in solving volume problems have been described by several studies (e.g., Battista \& Clements, 1996, 1998). For example, the findings of Battista and Clements' (1998) study revealed that close to $29 \%$ of the fifth-graders $(n=78)$ considered the rectangular arrays as the faces, but omitted cubes in the interiors of the array, and that these fifth-graders were found to use the volume formula incorrectly, in addition to five students who used the volume formula merely by rote. Memorizing volume formulae without understanding was also found in the study of Vasilyeva et al. (2013). Moreover, Battista and Clements $(1996,1998)$ suggested that students' difficulty in understanding the structure of 3D rectangular arrays resulted from being less able to see 3D cube arrays arranged in coordination. They also argued that only having students stack cubes without reflection (e.g., thinking about the spatial structure of the 3D arrays and the layer structuring of the arrays) does not sufficiently promote understanding of the structure of 3D arrays because students may only focus on physical manipulation rather than on their thinking.

\section{Developing Children's 3D Geometric Knowledge by Providing Dynamic Representations}

Providing dynamic representations in a 3D model, for which depth cues are provided in the diagrams and for which the dynamic representations are linked, facilitates children's generation of mental images and mental transformation between 2D and 3D representations based on the visual information (Shaffer \& Kaput, 1999). Specifically, the use of dynamic software for geometry teaching and learning permits students to look for patterns, check the properties of figures, and visualize transformation by manipulating a shape (Battista, 2007; Guven, 2012), in addition to physical manipulations (Hawes, Moss, Caswell, Naqvi, \& Mackinnon, 2017). As the findings of Guven's (2012) study illustrated, eighth-grade students' understanding of geometric transformation significantly benefited more from receiving a curriculum involving the use of the dynamic geometry software Cabri than the other group whose curriculum involved only isometric and dotted worksheets.

To aid children's understanding of volume measurement, Huang (2015a) examined the effectiveness of two sets of computer-based curricula involving solid volume measurement with different amounts of geometric knowledge for enhancing fifth-graders' competence in solving solid volume problems. One experimental group received the GKVM curriculum, in which the Cabri 3D software (Cabrilog Company, 2009) and flash media were used in PowerPoint ${ }^{\circledR}$ format to demonstrate the geometric properties of solids and the measurement of solid volumes with dynamic supports. The other group received the curriculum that involved concepts of solid volume measurement (VM curriculum), in which the volume formula was exhibited with static figures and textual descriptions in PowerPoint ${ }^{\circledR}$ format, but no dynamic figure was provided. Although both curricula contained similar subjectmatter components and cube-stacking operations regarding volume measurement, the GKVM curriculum highlighted the connections between the geometric understanding required to explore the structure of 3D cube arrays and the volume formula for volume measurement using dynamic geometric software. In contrast, the VM curriculum, similar to the conventional textbook unit on volume, emphasized the naming and measurement of the side lengths of three dimensions of a cube and the discovery of the volume formula based on demonstration with static figures and arithmetic computation of volume, while de-emphasizing the geometric knowledge embedded in volume measurement. The GKVM group outperformed the VM group in solving volume problems as a whole, as well as in solving problems that required conceptual understanding of volume measurement such as explaining the meaning of the volume formula.

The promising results presented by the previous study imply that a guided instructional intervention highlighting explorations of the properties of 2D and 3D objects and connections between the layer structure of 3D arrays and the volume formula through cube-stacking and the use of dynamic geometric programs may facilitate children's conceptual understanding of volume measurement concepts and their ability to solve volume problems.

\section{Linking Concepts of Solid Volume Measurement to Liquid Volume and Displaced Volume}

In a mathematical sense, capacity refers to the amount filling a hollow shape (Kerslake, 1976). Liquid volume and capacity are considered conjointly (Dickson et al., 1984; Kerslake, 1976). Dickson, Brown, and Gibson (1984) pointed out differences between solid and liquid volume measurement: (a) because liquids have no fixed shape, the notion of conservation (i.e., the volume of a liquid remains the same, regardless of the shape of the container) is needed to understand liquid volume; (b) different units are used to measure the volumes of solids (i.e., cubic centimeters or meters) and liquids (i.e., cubic centimeters or liters). Despite the differences in solid and liquid volume measurement, concepts of spatial measure involving notions of spatial extent and the spatial structure of $3 \mathrm{D}$ objects are required for solving solid volume problems and capacity problems.

Displaced volume, which involves the concept and procedures for volume measurement, is an advanced topic (Bell et al., 1975; Dickson et al., 1984). Bell, Hughes, and Rogers (1975) suggested that instruction on displaced volume involves the placement of a sinking object into a container of water to displace some of the water, causing 
the water level to rise. Through observation and displacement experiments - for example, submerging an object in a calibrated bottle and describing the difference between the old and new water levels - children can learn that an object submerged in water displaces a volume of water exactly equal to the volume of the object (The University of Chicago School Mathematics Project, 2012). Specifically, a displacement method is demanded to determine the volumes of irregularly shaped objects, for which the use of volume formulae is difficult or impossible.

\section{Understanding of Mathematical Knowledge for Transfer Problem Solving}

By adopting the metaphors of networks of mental representations, Hiebert and Carpenter (1992) claimed further that understanding occurs when relationships between different mental networks are connected into increasingly structured networks, including the connections within and between networks. Recognizing similarities and differences between pieces of mathematical information may facilitate the growth of mental networks of knowledge. Thus, the more organized the mental networks become, the more understanding that develops.

Most learning involves an enrichment of existing knowledge, which contains inference-making based on prior knowledge. This prior knowledge that is well understood and that is connected to related ideas fosters learning more than prior knowledge that is less understood (Hiebert \& Carpenter, 1992). Accordingly, to support the development of children's ability to solve problems and reasoning, cognitive researchers (e.g., Resnick, 2010) heavily emphasize children's understanding of the domain knowledge of a subject and application of skills that they have learned to solve new problems efficiently.

Concepts of solid volume measurement serve as a base for the understanding of water volume and displaced volumes. As Lehrer (2003) suggested, the development of measurement concepts may help students build linkage among various measures. Although little evidence is available to support the notion that a conceptual understanding of solid volume measurement based on a support of geometric knowledge promotes children's grasping of the notions of capacity (e.g., water volume) and displaced volume, a clear perception of the relationships among interior and exterior volumes is expected to facilitate further application for the learning of these concepts.

\section{The Guided Instructional Approach for Teaching Volume Measurement}

Battista (2003) suggested that leading inquiry-based activities through problems which encourage children to discover, reflect on and discuss enumeration strategies is critical for strengthening children's abilities to solve volume problems. This perspective serves as fundamental ground for a guided instructional approach, in which teachers play the role of facilitator of discussion for supporting students' engagement in problem-solving activities and explaining their mathematical thinking (Hseih \& Huang, 2013; Huang, 2015a, 2017).

The guided instructional approach, in which instructors provide organized materials that incorporate children's prior knowledge and learning opportunities in observation, manipulation, and discussion of the problems they solved, is based on studies on area measurement instruction (Huang, 2017) and volume measurement teaching (Huang, 2015a). The effectiveness of the approach for enhancing children's ability to solve measurement problems involving area and volume is evident in these previous studies.

\section{The Research and Study Hypotheses}

This research included two related studies, Phase 1 and Phase 2, investigating the same participants' learning outcomes. In both phases, the same teacher, who had 19 years of teaching experience, implemented both curricula using the same amount of teaching time and the same guided instructional approach that used teaching manuals and PowerPoint ${ }^{\circledR}$ materials.

The following two questions were posed, with one for each phase: (1) what are the effects of the two instructional treatments, which involved the same instructional approach and teaching time but stressed a different treatment of volume measurement- namely, a conventional curriculum that emphasizes the numerical notions of volume measurement (VM) and an enriched curriculum that highlights the connection between geometric knowledge of 2D and 3D shapes and volume measurement (GKVM), with regard to strengthening children's ability to solve solid volume problems? and (2) what are the potential effects of the two instructional treatments mentioned above on children's later performance of solving capacity and displaced volume problems? If there were differences, the possible reasons that the children reported as helping them significantly with their later performance when solving problems involving capacity and displaced volume were investigated.

The research tested two hypotheses. For Phase 1, hypothesis 1 tested that children who received the GKVM instructional treatment would gain a better understanding of the volume formula for rectangular solids and competence to solve volume problems than would children who received the VM instructional treatment. For Phase 
Q1. The jelly is a cuboid with length, width and height of $4 \mathrm{~cm}$ each. What is the volume of the jelly in cubic centimeters?

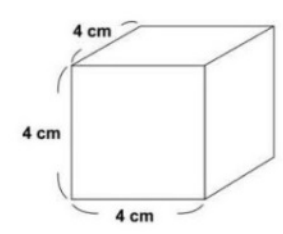

Q2. A cuboid is $7 \mathrm{~cm}$ long, $5 \mathrm{~cm}$ wide and $4 \mathrm{~cm}$ high. Ting says, "the volume of the cuboid is $7+5=12,12 \times 4=48\left(\mathrm{~cm}^{3}\right)$." Do you agree with her? Why or why not?

Figure 1. Examples of numerical volume calculation (Q1), mathematical judgment (first part of Q2), and explanation (second part of Q2) problems

2, hypothesis 2 tested that children's performance in solving problems involving water volume and displaced volume would differ between the GKVM and VM groups.

\section{PHASE 1}

\section{Method}

Research Design. A quasi-experimental design, which was conceptually similar to that of Huang (2015a), was used to examine the effects of the treatments. Although the two sets of curricula (GKVM and VM) were similar to those used in the previous study, the difference between the current and the previous study was that more cubestacking physical operations were involved in the VM treatment than were offered by the GKVM treatment. Children's understanding of volume measurement was assessed by paper-and-pencil assessments involving concepts of volume measurement and numerical calculations for solid volumes.

\section{Participants}

The participants were 53 fifth-graders from a public elementary school in an urban district of Taipei, Taiwan, inhabited largely by middle-class families. The VM group comprised 26 children (14 boys and 12 girls) with the mean age of 11.12 years (133.42 months; standard deviation [SD] $=3.34$ months). The GKVM group included 27 children (13 boys and 14 girls) with the mean age of 10.97 years ( 131.67 months; $S D=4.57$ months). All participants had already learned the basic concepts of volume, the meaning of $1 \mathrm{~cm}^{3}$, and the construction of 3D solids using unit cubes, but they had received no formal instruction in solid volume measurement or volume formulae. A $t$ test revealed no significant difference between groups in terms of their mathematics achievement scores from the semester prior to the study $(t[51]=1.13, p=0.26)$.

\section{Materials and Procedure}

Problem types. All treatments involved three types of problem requiring different levels of mathematical thinking and responses, based on Huang (2015a, 2017): numerical volume calculation (NVC), mathematical judgment (MJ), and explanation (EXP) problems. Examples of the three types of problem are shown in Figure 1.

NVC problems required knowledge of the arithmetic equations used to determine volume and the output of numerical answers, representing calculation skills. MJ problems demanded correct judgment of a given solution statement. EXP problems, which aimed to evaluate the children's understanding of volume measurement, required written explanations of responses to corresponding MJ problems. Thus, the MJ and EXP items required conceptual understanding and mathematical thinking involving high cognitive demand (i.e., high-level thinking, see Henningsen \& Stein, 1997; Resnick, 2010) such as explaining, reasoning, and reflections on the problems with which they were engaged.

Mathematical content of instructional treatments. Two sets of curricula (GKVM and VM) in PowerPoint ${ }^{\circledR}$ format were implemented. The curricula consisted of different combinations of the following seven subject-matter elements underlying the teaching problems: (A) the attributes of volume and the $1-\mathrm{cm}^{3} \mathrm{cubes}$ used to measure volume; (B) observation and direct and indirect comparison of the volumes of rectangular solids and 3D solids 


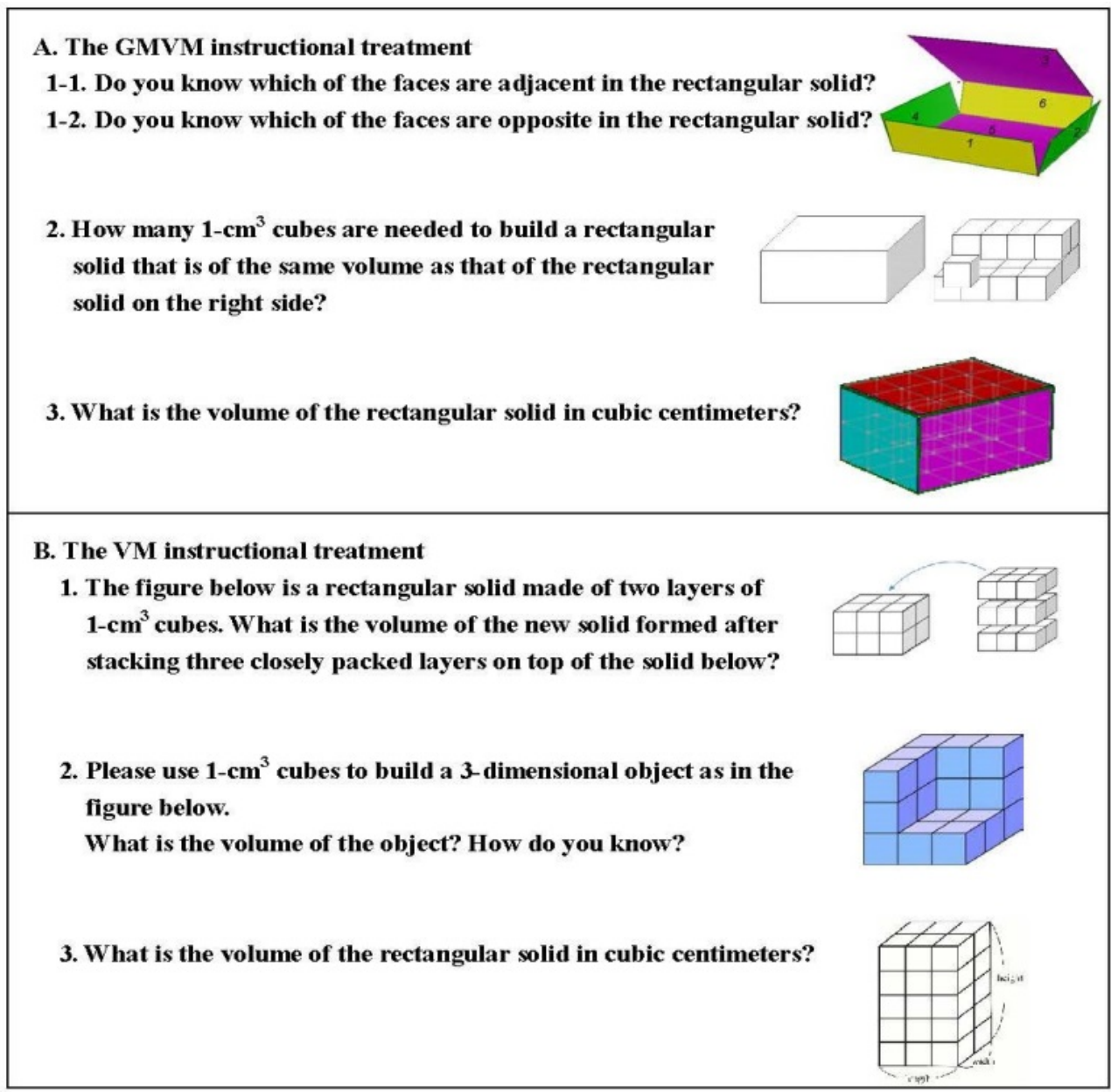

Figure 2. Examples of the dynamic figures exhibited in the GKVM treatment and the static figures displayed in the VM treatment

represented in two dimensions; (C) the discrete meaning of volume, imparted by building 3D solids (or filling containers) with identical cubes and then counting the cubes. Component $C$ was enlightened through the following activities: (i) encouraging students to engage in building 3D objects and cube filling in a given rectangular container $(4 \times 3 \times 2 \mathrm{~cm})$ by using $1-\mathrm{cm}^{3}$ cubes and $2 \times 2 \times 2$ blocks, and (ii) defining the base and height of a rectangular solid and their measures; (D) deriving the volume formula and using formulae to determine solid volumes; (E1) exploring the properties of rectangular prisms and related 3D spatial knowledge, including relations between 2D and 3D rectangular prisms; (E2) probing the structure of rectangular arrays through cube-stacking manipulation, including exploring separate views (front, top, and side) of rectangular arrays of stacked cubes; and (F) reasoning about volume formulae, with a focus on deriving the formulae for the volumes of common shapes, such as parallelepipeds and right-angled triangular prisms, based on knowledge of rectangular solid volume measurement and its formula.

In the GKVM treatment, the Cabri 3D dynamic software and flash media were used to illustrate operations for teaching problems involving elements E1 and E2, described above, including geometric movements, folding nets for rectangular solids to make rectangular prisms, and stacking cubes to build rectangular solids. In contrast, the VM curriculum did not include elements E1 and E2. Thus, no illustrations of geometric motions or dynamic figures were provided for the VM treatment; static figures with textual descriptions were exhibited. Also, there were more cube-stacking physical operations (three manipulation cases) than offered by the GKVM treatment (one manipulation case). Examples of the content of the two treatments are shown in Figure 2.

As for the teaching problems, the GKVM curriculum contained 36 question blocks and incorporated subjectmatter elements A-F. The curriculum consisted of two parts: (1) the first part comprised 21 question blocks addressing geometric shapes and movements and concepts of volume measurement and methods for measuring solid volumes, and (2) the second part included 15 question blocks addressing volume measurement of right-angled triangular prisms and parallelepipeds and reasoning about the formulae of these common shapes based on $\mathrm{v}=1 \times$ $\mathrm{w} \times \mathrm{h}$ and $\mathrm{v}=\mathrm{b} \times \mathrm{h}$. 
The VM curriculum contained 51 question blocks and incorporated subject-matter elements A-D and F. The curriculum included two parts: (1) the first part comprised 30 question blocks involving concepts of measurement of rectangular solid volume with static pictorial representations, as well as more cube-stacking opportunities, but de-emphasized geometric knowledge, and (2) the second part included 21 question blocks addressing the same subject-matter elements as in the second part of the GKVM curriculum. It is noteworthy that the second parts of the two sets of curricula were similar, except that no dynamic pictorial representation was supplied in the VM treatment.

A teaching manual and cubes were provided for each treatment. Each manual illustrated a possible learning process in which the instructor anticipated students' ways of thinking and offered ways to provide guidance through questioning and answering (see Appendix I). For each instructional session, a research assistant operated computers in the classrooms.

Pre-test and post-test. The pre- and post-tests were equivalent assessments. To evaluate children's understanding of the attributes of volume measurement and their application in daily life, short-answer (SA) problems that demanded short descriptions expressing the meaning of various measurements and their applications for measures in daily life were included. Each test, which could be completed in 40-45 minutes, consisted of four NVC problems, one SA problem, four MJ-EXP problem pairs, and two multiple-choice (MC) problems with corresponding SA (MC-SA) problem pairs (see Appendix II).

The reliability of the pre- and post-tests was examined by administering paper-and-pencil tests to 24 fifthgraders enrolled in a public school in New Taipei City, Taiwan. The initial mean pre-test and post-test values were $29.89(S D=13.50)$ and $27.68(S D=10.32)$, respectively. The correlation of the two tests was $0.71(p<0.001)$.

Procedure. The procedure included four steps. (1) Participants took the pre-test individually prior to the treatments. (2) The first parts of the curricula (volume measurement of rectangular solids) were implemented in the respective groups in five 40-minute sessions. (3) The post-test was administered immediately thereafter (one week after the pre-test). (4) The second parts of the curricula were implemented in one 40-minute session each. All class sessions were videotaped.

\section{Scoring and Data Analysis}

During the intervention period, two independent observers took notes and verified the fidelity of treatment implementation using the checklist used by Huang (2015a, 2017). Checklist items were used to assess the consistency of the two treatment groups in terms of instructional content, teaching activities, teaching time, use of teaching aids, the teacher's circulation through the classroom, and the type and amount of the teacher's encouragement. All checklist items showed at least $90 \%$ inter-observer agreement.

Two raters and the first author co-operatively developed a rubric scheme for the scoring of the three main problem types based on that used by Huang (2015a). NVC problem scores ranged from 0 to 5 , based on the arithmetic equation and numerical answers provided by the children. For the multiple-choice and MJ problems, scores of 0 or 2 were given. Scores for the EXP items corresponding to the MJ items ranged from 0 to 2, based on the accuracy and completeness of the written explanations. The corresponding MJ and EXP item scores were then summed to obtain a total score for each problem pair. Unweighted scores were used for these three problem types.

Finally, the SA item scores ranged from 0 to 5, based on the accuracy and completeness of the children's written descriptions. Because knowledge of the attributes of volume measurement, its application to everyday problems, and how to measure volume require an understanding of the volume concept and higher-level mathematical thinking, the SA item scores were weighted by doubling the raw scores. The total possible pre- and post-test scores were 70 each.

To further examine children's performance, various subscale scores were defined and compared between groups. The NVC subscale consisted of total scores on NVC problems that required arithmetic operations, whereas the conceptual understanding (CU) subscale, which was assessed to examine the children's conceptual understanding of solid volume measurement, consisted of total scores on the MJ-EXP pairs, SA item, and MC-SA pairs. The pre-test and post-test subscale scores were compared. Children's ideas for responding to the EXP items on the post-test were categorized into written explanations and arithmetical operations (or equations) based on their responses.

\section{Coding Reliability}

Based on two raters' independent scoring of 27 randomly selected post-tests, inter-rater agreement (Pearson's $r)$ reached $0.99(p<0.01)$ for the NVC and MJ problem scores. Inter-rater reliability $(k)$ for the EXP and SA problem scores was $0.83(p<0.01)$. 
Table 1. Mean Pre-Test and Post-Test Volume Measurement Scores by Treatment Group

\begin{tabular}{|c|c|c|c|c|c|c|c|c|c|}
\hline \multirow{2}{*}{ Group } & \multirow{2}{*}{$n$} & \multicolumn{2}{|c|}{ Pre-test } & \multicolumn{3}{|c|}{ Post-test } & \multirow[b]{2}{*}{$\boldsymbol{F}$} & \multirow{2}{*}{$\boldsymbol{P}$} & \multirow{2}{*}{ ES } \\
\hline & & $M$ & $S D$ & $M$ & $S D$ & Adjusted $M$ & & & \\
\hline \multicolumn{10}{|c|}{ Total score } \\
\hline GKVM & 27 & 39.85 & 13.45 & 54.72 & 9.04 & 53.30 & \multirow{2}{*}{6.45} & \multirow{2}{*}{$<0.01$} & \multirow{2}{*}{0.11} \\
\hline VM & 26 & 35.08 & 14.72 & 46.14 & 13.78 & 47.56 & & & \\
\hline \multicolumn{10}{|c|}{ NVC subscale } \\
\hline GKVM & 27 & 15.19 & 5.61 & 18.76 & 1.75 & 18.37 & \multirow{2}{*}{3.22} & \multirow{2}{*}{0.08} & \multirow{2}{*}{0.06} \\
\hline $\mathrm{VM}$ & 26 & 12.56 & 6.21 & 16.37 & 4.85 & 16.76 & & & \\
\hline \multicolumn{10}{|c|}{ CU subscale } \\
\hline GKVM & 27 & 24.67 & 8.84 & 35.96 & 8.30 & 35.26 & \multirow{2}{*}{6.90} & \multirow{2}{*}{$<0.01$} & \multirow{2}{*}{0.12} \\
\hline VM & 26 & 22.52 & 10.50 & 29.77 & 9.85 & 30.47 & & & \\
\hline
\end{tabular}

Note. $M=$ mean; $S D$ = standard deviation; $E S$ = effect size; GKVM = geometry and volume measurement intervention; VM = volume measurement intervention; NVC = numerical volume calculation; $C U$ = conceptual understanding

\section{Results}

A $t$ test was conducted to examine the pre-test scores of the two groups. The results showed no significant difference $(t[51]=1.23, p=0.22)$. Analysis of covariance (ANCOVA), with total pre-test scores serving as the covariate, showed a significant main effect of the interventions on the total post-test scores, $F(1,50)=6.45, p<0.01$, partial $\eta^{2}=0.11$. The GKVM group performed better than the VM group (Table 1).

The post-test NVC and CU subscale scores of the two groups were compared using ANCOVA, with the pretest scores serving as the covariate. The treatment effect on the NVC subscale scores showed that the GKVM group obtained slightly higher scores than the VM group. This difference did not reach statistical significance at the 0.05 level, $F(1,50)=3.22, p=0.08$, partial $\eta^{2}=0.06$. The CU subscale scores were significantly higher in the GKVM group than in the VM group, $F(1,50)=6.90, p<0.01$, partial $\eta^{2}=0.12$ (see Table 1 ).

In addition, children's responses to these items, such as written equations, diagrams, and interpretations of mathematical ideas, may manifest their ways of thinking (Goldin, 2003) and, to some extent, their understanding obtained from the interventional curricula. To illustrate the tendency in the ways of children's explanations of solving solid volume problems in the two groups, examples of children's written explanations for the MJ-EXP items Q2 (comparison of the volumes of two rectangular solid figures) and Q4 (making mathematical judgements of a solution statement in terms of the given base area and height of a rectangular solid frame) in the post-test are shown in Figure 3.

As shown in Figure 3, in response to Q2, child GKVM_A in the GKVM group explained her understanding of conceptual knowledge of volume measurement, including comparison of the base areas and heights of the two rectangular solids and the idea that two different solid shapes may have similar volume measures. In contrast, child VM_C in the VM group used formulae and numerical calculations to represent the use of procedural knowledge of volume measurement to explain her reasoning, without detailed explanation. In response to Q4, child GKVM_B in the GKVM group sought to explain his spatial reasoning based on the figure provided, which represented the geometric knowledge underlying volume measurement, and used equations as well as numerical calculations to justify his ideas. In contrast, child VM_D in the VM group provided an equation, which represented procedural knowledge of volume measurement, and briefly communicated his disagreement with the solution statement. 


\section{Examples of children's explanations for the MJ-EXP problems, Q2 and Q4,} in the post-test of Phase 1

1. Solids $\mathrm{A}$ and $\mathrm{B}$ are filled with $1-\mathrm{cm}^{3}$ cubes. Please answer questions according to the figures below.

A

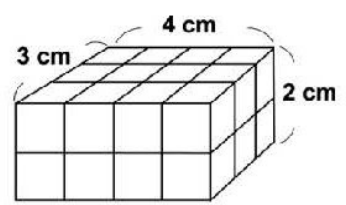

$6 \mathrm{~cm}$

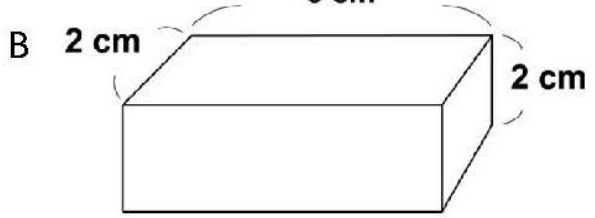

Joe says, "The volume of solid A is the same as the volume of solid B." Do you agree with him? Why or why not? Please write down your ideas.

\begin{tabular}{|c|c|}
\hline Example of the GKVM Group: A & Example of the VM Group: C \\
\hline 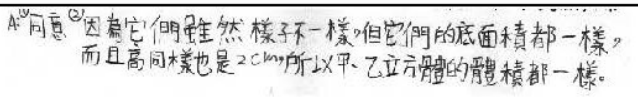 & 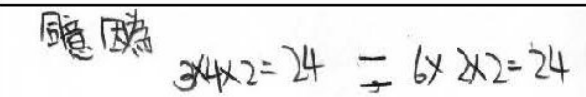 \\
\hline
\end{tabular}

English translation: "Yes, I agree. Although they look different, their base areas are the same and English translation: "Yes, I agree. Because $3 \times 4 \times$ their heights are both $2 \mathrm{~cm}$ as well. So, the two rectangular prisms have the same volume."

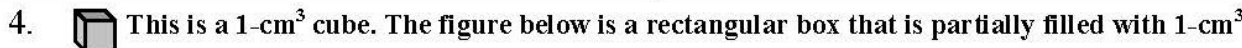
cubes. Please answer the following questions.

(1) Tom says, "The area of the base of the rectangular box is $3 \times 3=9\left(\mathrm{~cm}^{2}\right)$ and the height is $3 \mathrm{~cm}$." Do you agree with him? Why or why not? Please write down your ideas.

(2) Do you know how many $\square$ in total are needed for Tom to completely fill the rectangular box? Please use arithmetic operations to express your ideas.

$$
2=24=6 \times 2 \times 2 \text {." }
$$

\begin{tabular}{|c|c|}
\hline Example of the GKVM Group: Child B & Example of the VM Group: Child D \\
\hline 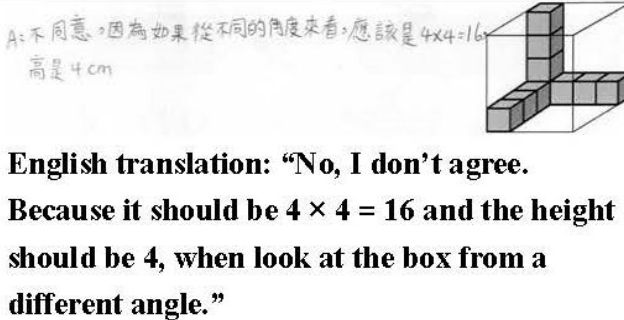 & $\begin{array}{l}4 \times 4: 16 \\
\text { English translation: "4 } 4 \mathbf{4}=16 " \text { and } \\
\text { "No, I do not agree. Because he missed one } \\
\text { block." }\end{array}$ \\
\hline
\end{tabular}

Figure 3. Example of children's written explanations for their reasoning in Phase 1 study

Taken together, the way children responded to the MJ-EXP items in the two groups were dissimilar. In explaining and providing justification, the children in the GKVM group showed stronger tendency than those in the VM group to describe notions of how to obtain the solution and reasons for their suggestions, which represented conceptual knowledge of volume measurement. The children in the VM group were prone to using arithmetic equations (or numbers) or short statements to explain their reasoning.

\section{Discussion}

The main result of the Phase 1 study was that the GKVM treatment yielded better student performance in problem solving than did the VM treatment under the same implementation conditions, in terms of computerbased instruction, teaching time, and guided instructional approach. The results supported hypothesis 1. 
The findings are consistent with the perspectives that students' understanding of mathematics can be constructed through the design of learning environments where curricula embedded with coherently organized subject matters are given by guided instruction that calls for students' thinking and reasoning (Hiebert \& Carpenter, 1992; Resnick, 2010). With the guided instruction approach, children in the GKVM group engaged in physical manipulations (cube stacking) and exploring (e.g., the separate views [front, top, and side] of rectangular arrays of stacked cubes) and discussing the layer structure of 3D cube arrays exhibited via static and dynamic software. These cognitive processes, which involve constructing referential connections between corresponding elements (e.g., geometric knowledge and volume measurement concepts) and matching structures in different representations, lead to conceptual understanding (Braithwaite \& Goldstone, 2015; Seufert, 2003). This in turn promotes an enrichment of mental network of knowledge.

Children's understanding of solid volume measurement (i.e., seeing the connections among units, arrays, and dimensionality) in the geometric context supported by GKVM treatment facilitates their spatial and measurement reasoning, which in turn leads to a deeper understanding of the measurement of common prism volumes and volume formulae. This understanding also promoted the ability of the GKVM group to solve problems requiring conceptual understanding (the CU subscale). In contrast, the VM group's performances on the post-test as a whole and the CU subscale were inferior to those of the other group even though cube-stacking physical operations were provided for the VM treatment. These results may be due to a lack of support involving the elements related to geometric explorations in the VM interventional curriculum.

As for solving the NVC problems, the results showed no difference between the two groups. The current result is in accordance with the previous findings (Huang, 2015a), which indicated equivalent abilities in the two groups to solve the NVC problems similar to volume calculation problems in textbook exercises. Children who understand dimensionality and who are able to determine the side lengths of figures can calculate volumes using formulae (Dorko \& Speer, 2015). Indeed, the VM group obtained procedural knowledge of solid volume measurement for solving numerical volume calculation problems from the VM treatment. However, such procedural knowledge and calculation skills in determining solid volumes were not strong enough to advance the VM group's performance on the CU subscale.

\section{PHASE 2}

\section{Description of the Phase 2 Study and Participants}

All 53 participants took the capacity pre-test and received a similar set of capacity instruction after Phase 1 . The pre- and post-tests consisting of capacity and displaced volume measurement problems were administered before and after the capacity curriculum was implemented. Additionally, to obtain the children's viewpoints on applying previously learned volume measurement knowledge to the solving of advanced volume problems, one-on-one interviews were conducted.

\section{Materials and Procedure}

Mathematical content of the capacity curriculum and instruction. A capacity curriculum in PowerPoint ${ }^{\circledR}$ format with dynamic pictures was developed and then implemented. The curriculum addressed the following four subject-matter elements underlying the teaching problems: (A) exploring the relationships between solid and liquid volume measurement; (B) using a calibrated bottle filled with water to measure the volumes of 3D objects (prisms and irregularly shaped objects); (C) measuring the volumes of irregularly shaped objects by water displacement; and (D) determining the interior and external volumes of a container with thickness, including measuring the exterior and interior bases and depth of a container with thickness and boxes with and without lips.

Procedure. The procedure comprised three steps similar to those used in Phase 1 . The capacity curriculum was implemented in three 40-minute sessions in one week. All class sessions were videotaped.

Pre-test and post-test. The pre-test and post-test were equivalent assessments. Each test consisted of eight NVC items, one SA item, three MJ-EXP pairs, and three SA-EXP pairs (see Appendix III). The skills needed to solve the NVC, MJ, EXP, and SA problems were similar to those required in Phase 1.

The reliability of the pre-test and post-test was examined by 24 fifth-graders enrolled in a public school in New Taipei City, Taiwan. Two raters independently scored the tests; the inter-rater agreement (Pearson's $r$ ) reached 0.99 $(p<0.01)$ for the NVC and MJ item scores. Inter-rater reliability $(k)$ for the SA and EXP problem scores was 0.93. The initial mean pre-test and post-test scores were $48.06(S D=23.47)$ and $46.42(S D=26.37)$, respectively. The correlation between the two tests was $0.79(p<0.001)$.

To obtain children's viewpoints on the benefits of the previous volume measurement lesson for solving advanced volume problems, one-on-one interviews were conducted after the post-test by asking the questions "Did 
Table 2. Mean Pre-Test and Post-Test Capacity Scores by Treatment Group

\begin{tabular}{|c|c|c|c|c|c|c|c|c|c|}
\hline \multirow{2}{*}{ Group } & \multirow{2}{*}{$n$} & \multicolumn{2}{|c|}{ Pre-test } & \multicolumn{3}{|c|}{ Post-test } & \multirow{2}{*}{$\boldsymbol{F}$} & \multirow{2}{*}{$\boldsymbol{P}$} & \multirow{2}{*}{ ES } \\
\hline & & $M$ & $S D$ & $M$ & $S D$ & Adjusted $M$ & & & \\
\hline \multicolumn{10}{|c|}{ Total score } \\
\hline GKVM & 27 & 48.43 & 28.32 & 106.35 & 35.50 & 105.73 & \multirow{2}{*}{4.29} & \multirow{2}{*}{$<0.05$} & \multirow{2}{*}{0.08} \\
\hline VM & 26 & 44.37 & 45.30 & 81.65 & 47.69 & 82.28 & & & \\
\hline \multicolumn{10}{|c|}{ NVC subscale } \\
\hline GKVM & 27 & 14.82 & 10.92 & 28.02 & 9.61 & 27.96 & \multirow{2}{*}{1.26} & \multirow{2}{*}{0.27} & \multirow{2}{*}{0.02} \\
\hline VM & 26 & 14.46 & 14.50 & 24.64 & 12.44 & 24.69 & & & \\
\hline \multicolumn{10}{|c|}{ CU subscale } \\
\hline GKVM & 27 & 33.61 & 23.64 & 75.93 & 27.37 & 75.36 & \multirow{2}{*}{5.18} & \multirow{2}{*}{$<0.05$} & \multirow{2}{*}{0.09} \\
\hline VM & 26 & 29.90 & 35.62 & 55.48 & 35.97 & 56.05 & & & \\
\hline
\end{tabular}

Note. $M=$ mean; $S D$ = standard deviation; $E S$ = effect size; GKVM = geometry and volume measurement intervention; VM = volume measurement intervention, NVC = numerical volume calculation; $\mathrm{CU}=$ conceptual understanding

the volume measurement lesson taught previously help you solve the problems involving water volume and displaced volume measurements? Why or why not?" The interviewees included 29 children who were randomly selected from the two groups (GKVM, $n=15$; VM, $n=14$ ). The interviewees' responses were audio-taped and transcribed for analysis.

\section{Scoring and Data Analysis}

The procedures and checklist for verifying the fidelity of curriculum implementation were the same as those used in Phase 1. All checklist items showed at least 90\% inter-observer agreement.

Two raters and the first author cooperatively developed a rubric scheme for the scoring of the four problem types. As in Phase 1, the NVC problem scores ranged from 0 to 5 . As the domain of displaced volume is more complicated than that of solid volume measurement (Bell et al., 1975; Dickson et al., 1984), and because a higher level of mathematical thinking was required to solve the SA, MJ, and EXP problems, the scores for these problems ranged from 0 to 5, based on the accuracy and completeness of the students' answers. For the MJ problems, scores of 0 or 5 were given. The procedure for obtaining the total scores for the MJ-EXP and SA-EXP pairs was the same as that used in Phase 1.

In the current study, the SA-EXP scores were weighted by doubling the raw scores for two reasons: (1) solution of the SA-EXP items demanded multiple mathematical concepts and volume measurement skills (e.g., understanding of interior and exterior volumes, comparing volumes of various containers with and without lids, explaining reasons for the mathematical judgements made for volume comparison, and how to measure the volumes of solid objects by using water displacement), and (2) these skills are the application of volume measurement concepts for solving complex daily life problems. Accordingly, the total possible pre-test and posttest scores were 140 each.

The pre-test and post-test NVC and CU subscale scores of the two groups were compared. The total CU subscale scores were calculated by summing the scores of the MJ-EXP pairs, SA item, and SA-EXP pairs. The procedure for calculating the total NVC and CU subscale scores was the same as used in Phase 1.

The categorization of the interviewees' viewpoints and reasons included three categories: (1) the concepts of volume and capacity are related, (2) the volume of a sinking object equals the volume of the displaced water, and (3) the water volume which rises is directly related to the volume of the immersed item (see Appendix IV). All of the interview data were independently analyzed by two raters.

Based on the two raters' independent scoring of 27 randomly selected post-tests, the inter-rater agreement $(r)$ on the NVC and MJ problem scores reached $0.99(p<0.01)$, and the inter-rater agreement $(r)$ on the SA and EXP problem scores was $0.96(p<0.01)$. The inter-rater agreement on the coding of the 29 interviewees' responses to the interview questions reached $95 \%$.

\section{Results}

The pre-test scores of the two groups did not differ, $t(51)=0.39, p=0.70$. ANCOVA of total post-test scores, with pre-test scores serving as covariates, showed a significant difference in total performance between the GKVM and VM groups, $F(1,50)=4.29, p<0.05$, partial $\eta^{2}=0.08$ (see Table 2). The GKVM group outperformed the VM group.

ANCOVA of the post-test NVC subscale scores, with pre-test scores serving as the covariate, showed no difference between groups, $F(1,50)=1.26, p=0.27$, partial $\eta^{2}=0.02$. ANCOVA of the post-test CU subscale scores 


\begin{tabular}{|c|c|}
\hline \multicolumn{2}{|c|}{$\begin{array}{l}\text { Examples of children's explanations for the SA-EXP, Q4, and MJ-EXP problems, Q6, } \\
\text { in the post-test of Phase } 2\end{array}$} \\
\hline \multicolumn{2}{|c|}{$\begin{array}{l}\text { Q4. Containers A, B, and C are made of wooden boards of 1-cm thickness. Mr. Lee measures the interior } \\
\text { and exterior sides of each box. Please explain your ideas for the questions below. } \\
\text { (2) A is a lidless box with interior length, width, and height of } 40 \mathrm{~cm} \text { each. C is a lidless box with } \\
\text { exterior length, width, and height of } 40 \mathrm{~cm} \text { each. Mr. Lee wants to completely fill the containers with } \\
\text { 1- } \mathrm{cm}^{3} \text { cubes. Which container holds more cubes, A or C? Why? }\end{array}$} \\
\hline Example of the GKVM Group: $\mathrm{E}$ & Example of the VM Group: $\mathrm{G}$ \\
\hline 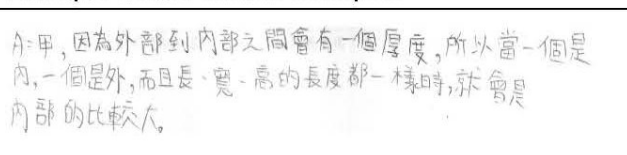 & 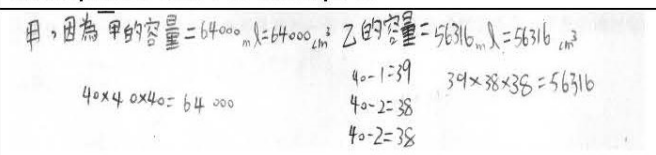 \\
\hline $\begin{array}{l}\text { English translation: "A. Because there is } \\
\text { thickness between the interior and exterior } \\
\text { [of a prism], when the interior length, width, } \\
\text { and height of one prism are the same as the } \\
\text { exterior length, width, and height of the other } \\
\text { prism, the capacity of the one with interior } \\
\text { [lengths] is larger than that of the other one } \\
\text { with exterior [lengths]." }\end{array}$ & $\begin{array}{l}\text { English translation: "A, because the capacity of } \\
A=64000 \mathrm{ml}=64000 \mathrm{~cm}^{3}, 40 \times 40 \times 40=64000 \\
\text { the capacity of } B=56316 \mathrm{ml}=56316 \mathrm{~cm}^{3}, 40- \\
1=39,40-2=38,40-2=38,39 \times 38 \times 38= \\
56316 . "\end{array}$ \\
\hline \multicolumn{2}{|c|}{$\begin{array}{l}\text { Q6. Triangular prism A is made of } 4 \text { layers of small triangular prisms. Ms. Wang places prism A on a } \\
\text { piece of 1-cm grid board. Please answer the following questions. } \\
\text { (4) The length, width, and height of rectangular prism B are } 2 \mathrm{~cm}, 10 \mathrm{~cm} \text {, and } 3 \mathrm{~cm} \text {, respectively. Ms. } \\
\text { Wang submerges prisms A and B into separate identical measuring cups that both contain } 80 \\
\text { milliliters of water. She then observed the new levels of water in each measuring cup. } \\
\text { Ginny said, "The water levels in both of the measuring cups rise by the same amount." Do you } \\
\text { agree with her? Why or why not? Please write down your ideas. }\end{array}$} \\
\hline Example of the GKVM Group: $F$ & Example of the VM Group: $\mathrm{H}$ \\
\hline 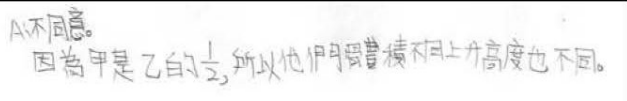 & 不同意因為算出来的年公不一样 \\
\hline $\begin{array}{l}\text { English translation: "No. I do not agree. } \\
\text { Because the volume of } A \text { is a half of [the } \\
\text { volume] of } B \text {, so the water levels do not rise } \\
\text { by the same amount." }\end{array}$ & $\begin{array}{l}\text { English translation: "No. I do not agree. } \\
\text { Because the outcomes calculated [for A and B] } \\
\text { are not the same." }\end{array}$ \\
\hline
\end{tabular}

Figure 4. Example of children's written explanations for their reasoning in Phase 2 study

showed a significant difference between groups, $F(1,50)=5.18, p<0.05$, partial $\eta^{2}=0.09$. The GKVM group showed superior performance (see Table 2).

The results showed that performance in the GKVM group was superior to that in the VM group. Furthermore, the mathematical ideas underlying the children's written explanations in response to the SA-EXP and MJ-EXP items on the post-test revealed differences in the groups' use of conceptual and procedural knowledge of volume measurement. Figure 4 shows examples of children's written explanations in the post-test for the SA-EXP item Q42 (comparison of the capacities of two prisms) and the MJ-EXP item Q6-4 (making mathematical judgements of a solution statement in terms of comparing the rising water levels of two prisms submerged in a measuring cup).

Responding to the SA-EXP item Q4-2, child GKVM_E in the GKVM group tended to apply conceptual knowledge of volume measurement to explain his reasoning through explaining why the interior capacity of one prism was larger than the exterior capacity of another prism. In contrast, child VM_G in the VM group was prone 
to use procedural knowledge such as equations and numbers to explain his ideas without interpretations (see Figure 4).

In response to the MJ-EXP item Q6-4, child GKVM_F in the GKVM group used a fraction and volume concepts to justify his disagreement with the solution statement. In contrast, child VM_H in the VM group briefly expressed his disagreement with the solution statement because of the results of his calculations (see Figure 4). The observed differences between groups in the children's use of conceptual and procedural knowledge of capacity seem to be consistent with the results of Phase 1.

\section{Interview Data}

All the interviewees from the two groups expressed that the treatment they had received in Phase 1 supported them in solving advanced volume problems because of close connections between measurements of solid volume and water volume. The interviewees' reasons for explaining the relationships between measurements of solid volume and water volume included: (1) the need for volume measurement skills for capacity calculation, (2) similar measuring methods, and (3) the equivalence between the volume of a sinking object and the volume of displaced water or the amount of water level rise (see Appendix IV).

For the GKVM group, 12 interviewees strived to describe the attributes of volume and capacity learned in the previous volume lesson to explain the relationships between measurement of solid volume and capacity. Furthermore, three interviewees described the differences between measuring volume and capacity, regardless of the relationships between the two measurements. For example, interviewee GKVM_G expressed:

$$
\begin{aligned}
& \text { "... There are differences in measuring interior volume and exterior volume [of an object] ... For } \\
& \text { volume calculations, the determination of external length, width, and height is needed, whereas } \\
& \text { calculation of a capacity should consider whether [the container] has or is without a lip. Also, you will } \\
& \text { get an incorrect calculation of capacity without considering the thickness [of that container]." }
\end{aligned}
$$

All interviewees from the GKVM group considered that solid volume measurement skills served as the base of capacity calculation, although three interviewees were less able to explain the relationships well. For example, interviewee GKVM_C indicated:

"If we jump to capacity without [learning] volume, this may lead to difficulty in understanding what
the teacher taught. For instance, in the class we used and filled cubes in the rectangular box. When
measuring the capacity of the box, the use of volume measurement learned earlier is needed. Put the
white cubes into the box and then calculate the volume, and then the capacity of the box can be found."

It is noteworthy that no interviewees from the GKVM group addressed the conversions between units of volume and capacity such as " $1 \mathrm{~cm}^{3}=1 \mathrm{ml}$." Additionally, four interviewees from the GKVM group pointed out the materials used or manipulations in the volume intervention, including the dynamic pictures in the PPTs and cube-stacking activities when they reported the benefits of the volume lesson taught previously.

As for the VM group, 11 interviewees endeavored to describe the relationships between volume measurement and capacity via pointing out that volume measurement skills served as the foundation of capacity calculations, although there was a lack of complete description in their statements. For example, interviewee VM_O used cursory terms such as "outer" and "inner" for describing the differences between measuring volume and capacity. He indicated:
"Volume and capacity are related. I think that the general meaning of capacity is about ... umm ... counting the number of items inside. Volume is the outer [measurement]. There are a few relationships between volume and capacity. That is, volume measurement counts the outer only, whereas capacity counts the inner."

Similar to those notions addressed by the GKVM group, the connections between measurements of solid volume, water volume, and displacement volume were indicated by the interviewees of the VM group such as "the approaches for measuring volume and capacity are similar" and ways of observing the changes in water levels to find the volume of a sinking item. Note that five interviewees of the VM group addressed " $1 \mathrm{~cm}^{3}=1 \mathrm{ml}$ " when they expressed the reasons. For example, one interviewee (VM_I) stated:

"Learning volume measurement will help us know ways to calculate the size of an object, the inner space of an object. As ' $1 \mathrm{~cm}^{3}$ equals $1 \mathrm{ml}$,' calculating the volume is also measuring its capacity." 
Moreover, one interviewee (VM_H) indicated:

"Learning volume measurement helps people know '1 $\mathrm{cm}^{3}=1 \mathrm{ml}$.' This is because I threw it [a 1-cm white cube] into the water [in a container]."

Looking closely at the explanations stated by the interviewees of the VM group who highlighted ' $1 \mathrm{~cm}^{3}=1 \mathrm{ml}$,' it seemed they considered that the relationships between volume measurement and capacity are generated from the conversions between units of volume and capacity.

Taken together, the interview data showed some similarities in the benefits of the two treatments, including (1) the recognition that concepts of volume and capacity are related, and (2) understanding that the approaches to calculating solid and liquid volumes look alike despite some differences between the two measurements, and (3) the volume of displaced water and the amount of water volume rise equal the volume of a sinking object. Despite these similarities, some differences existed in the verbal explanations expressed by the two groups. The interviewees from the GKVM group tended to describe the 3D characteristics of a solid, differences and relationships between measuring solid volume and water volume and the displacement method, instead of conversions between units of volume and units of capacity. In contrast, interviewees from the VM group were more likely to address the category acquiring conversions between units. Ideas about counting and calculation seemed to be the core of their descriptions of solid volume measurement and capacity.

\section{Discussion}

The results of Phase 2 showed that previous treatment using the GKVM curriculum improved the children's performance in solving capacity and volume displacement problems after receiving identical capacity instruction, relative to treatment using the VM curriculum. These results support hypothesis 2 . These profits were manifested in superior performance on the CU subscale. The VM treatment aided the children's acquisition of the liquid and displaced volume measurement skills, such as the calculation of a liquid volume that pertains to procedural knowledge, but it was less beneficial than the GKVM curriculum in terms of overall and CU subscale performances.

Generally, interviewees from the two groups considered that the curricula provided were helpful for later problem solving. In spite of some similarities in the benefits of the two treatments, differences between the two groups appeared in the interviewees' verbal responses. As the two groups received identical capacity instruction, these differences can be attributed to the varied volume measurement learning experiences in Phase 1.

The interview data showed that the interviewees from the GKVM group were more likely than those from the VM group to describe the 3D characteristics of a solid, and differences and relationships between volume measurement and capacity as well as the displacement method. Specifically, four interviewees from the GKVM group explicitly pointed out the dynamic representations and cube-stacking activities in the previous volume curriculum, which impressed them while learning about solid volume measurement. This in turn may facilitate the comprehension of procedural knowledge demanded for the conceptual understanding involved in solid volume measurement (Battista, 2007) and measurement reasoning.

In contrast, the interviewees from the VM group were prone to pay attention to measurement procedures and conversion units between volume and capacity, rather than the attributes of volume and capacity. To some extent, the interview data supported the observed differences between the two groups in terms of the children's written explanations responding to the SA-EXP and MJ-EXP items.

The results support Hiebert and Carpenter's (1996) and Novick and Hmelo's (1994) perspectives that a deeper understanding of the subject being taught, by knowing what method worked out and why, enables a student to relate the method to the subject (or problem). Such understanding can facilitate application performance in problem solving. These findings also suggest that children construct knowledge based on prior knowledge and experience (Braithwaite \& Goldstone, 2015; Seufert, 2003), and that the level of understanding of a new domain (e.g., capacity and displaced volume) depends on previous knowledge of related procedures and concepts (e.g., solid volume measurement).

\section{GENERAL DISCUSSION}

This research focused on curricula and instruction for spatial measurement, more specifically approaches to enhancing fifth-grade children's understanding of volume measurement for various materials. Findings demonstrate, compared to a control group receiving the volume measurement treatment that emphasized measurement procedures and volume calculations, the efficacy of implementing an enriched curriculum involving geometric knowledge and volume measurement for improving students' learning of volume measurement. Phase 1 showed that the fifth-graders who received the GKVM treatment obtained greater gains on the measures demanding a conceptual understanding of volume measurement and ability to solve volume problems than the 
VM group that received the VM treatment. The Phase 2 study showed that children in the GKVM treatment group also demonstrated gains relative to the control group on the advanced volume task involving water volume and displacement volume. This is an advanced finding and one that provides preliminary evidence that solid volume measurement training may facilitate learning achievement of advanced volume measurement. Furthermore, the two related studies demonstrated the effectiveness of implementing an integrated curriculum incorporating volume measurement with 2D and 3D geometry knowledge through dynamic software to volume measurement instruction, an approach that aims at developing children's understanding of measurement concepts pertaining to spatial measurement.

\section{On Enhancing Children's Ability to Understand Solid Volume Measurement}

Our findings add to a growing body of research which has found that geometric knowledge is important for learning measurements involving spatial notions such as geometric conceptualization and reasoning (Battista, 2007). A greater degree of mental adeptness in terms of geometric knowledge of shapes and layer structure of 3D cube arrays, in addition to numerical calculation skills, is a significant prerequisite for children's development of measurement skills for volume measurement.

Providing problem-solving activities integrating effective media can evoke children's intuitive understanding and transformational reasoning (Guven, 2012; Shaffer \& Kaput, 1999). For example, the children who received the GKVM treatment with a strong emphasis on developing the structure of 3D arrays of cubes through dynamic programs technology, in addition to concrete cube-stacking operations, which allowed them to "envision the transformations that these objects undergo and the sets of results of these operations" (Simon, 1996, p. 201). Such activities that provide visual and kinesthetic supports for the acquisition of cognitive representations may aid operations executed in mental images and reasoning (Shaffer \& Kaput, 1999), which in turn facilitates linking the layer structure of 3D arrays and understanding of the volume formula (Hsieh \& Huang, 2013; Huang, 2015a).

Like the conventional curriculum, the VM treatment stressed numerical volume calculations with concrete cube-stacking operations without the aid of elements of geometric knowledge through dynamic software. The VM group obtained skills for determining solid volumes by using the volume formula but had limited gains on constructing a comprehensive understanding of solid volume measurement. The VM treatment assisted the VM group to acquire the procedural knowledge of volume measurement. Nevertheless, without supports of the elements of geometric knowledge, the aid of the VM treatment showed insufficiency to help children construct a high-level understanding of solid volume measurement, such as seeing the layer structure and linking it to the volume formula. All these concepts pertain to conceptual knowledge of volume measurement.

Indeed, the effectiveness of the GKVM treatment was evident in the GKVM group's performance in solving the volume problems as a whole and the subscale requiring explaining reasoning and justification. The findings of Phase 1 imply that children following different curricula may focus their attention on different elements of knowledge highlighted in the received curricula, which in turn leads to their construction of knowledge with different levels of understanding (Henningsen \& Stein, 1997).

\section{On Strengthening Children's Ability to Measure Water Volume and Displacement Volume}

The findings of Phase 2 showed that children in the GKVM group also achieved better problem-solving performance in capacity and volume displacement, which requires a deeper level of understanding of volume measurement (Bell et al., 1975; Dickson et al., 1984). They reflected this deeper understanding in their interpretations of solid and water volumes and in their reasoning and justification. These findings suggest that the previously gained understanding of volume measurement did boost the children's problem-solving performance in the context of identical capacity instruction. As Hiebert and Carpenter (1992, p. 80) explained, "because understanding is generative, prior knowledge that has been understood is more likely to generate new understandings in new situations; relationships between prior knowledge and new material are more likely to be built." The quality of students' understanding of mathematics knowledge strongly influences what they learn and how they apply it to solve problems.

On the basis of the findings, children's ability to solve problems involving capacity and displacement volume can be fostered through providing sufficient mathematical experiences that are intended to encourage them to explore geometric knowledge underlying the volume measurement of a 3D object and discuss principles of volume measurement incorporated with their application to problem solving. Such in-depth explorations include indicating similarities (or correspondence) and differences between solid and water volume measurement and applications for displacement volume. 
The findings of Phase 2 showed that, compared to the GKVM group, the VM group was inclined to pay more attention to the calculation procedures and conversions between units of solid volume and units of capacity for volume measurement, which pertains to procedural knowledge of volume measurement, rather than to the attributes of various types of volume. These results perhaps emerged from the experience obtained from the VM treatment. That is, a previous learning situation in which procedural knowledge of volume measurement (e.g., volume determination and calculations) was emphasized may have led the children to focus on finding suitable formulae for numerical calculations but desalinating a conceptual understanding of volume measurement (Huang, 2015a). Prior experience in learning a subject may affect later outcomes of learning in a related domain (Seufert, 2003). Thus, we argue that children's abilities to understand advanced concepts and learn new materials depend strongly on their previously constructed knowledge, including what knowledge they construct and how they construct it at the beginning. Still, this viewpoint requires further examination.

\section{Limitations}

One limitation of the current study was that the number of participants in each group is insufficient to meet Creswell and Creswell's (2018) recommendation for an experimental study in which at least 30 participants are needed for statistical significant tests. It would be interesting to replicate this study while increasing the number of fifth-grade students.

\section{Conclusion}

The findings of the study indicate that geometric knowledge plays an essential role in children's learning of solid volume measurement. Furthermore, the understanding of solid volume measurement may have an important influence on later learning of capacity and displacement volume and performance in solving volume problems. Effective computer-based curricula integrated with geometric knowledge and volume measurement via the guided instruction approach, supported by empirical research, may contribute to the enhancement of students' ability to handle solid and water volume measurement.

\section{REFERENCES}

Battista, M. T. (2003). Understanding students' thinking about area and volume measurement. In D. H. Clements, \& G. Bright (Eds.), Learning and teaching measurement. 2003 Year book (pp. 122-142). Reston, VA: National Council of Teachers of Mathematics.

Battista, M. T. (2007). The development of geometric and spatial thinking. In F. K. Lester, Jr. (Ed.), Second handbook of research on mathematics teaching and learning: A project of National Council of Teachers Mathematics (pp. 843908). Charlotte, NC: Information Age Publishing.

Battista, M. T., \& Clements, D. H. (1996). Students' understanding of three-dimensional rectangular arrays of cubes. Journal for Research in Mathematics Education, 27(3), 258-292. https:/ / doi.org/10.2307/749365

Battista, M. T., \& Clements, D. H. (1998). Students' understanding of three-dimensional cube arrays: Findings from a research and curriculum development project. In R. Lehrer, \& D. Chazan (Eds.), Designing learning environment for developing understanding of geometry and space (pp. 227-248). Mahwah, NJ: Erlbaum.

Bell, D., Hughes, E. R., \& Rogers, J. (1975). Area, weight, and volume: Monitoring and encouraging children conceptual development. London, Great Britain: Thomas Nelson \& Sons.

Braithwaite, D. W., \& Goldstone, R. L. (2015). Effects of variation and prior knowledge on abstract concept learning. Cognition and Instruction, 33(3), 226-256. https:/ / doi.org/10.1080/07370008.2015.1067215

Cabrilog Company (2009). About Cabrilog history. Retrieved from http:/ / www.Cabrilog.com

Creswell, J. W., \& Creswell, J. D. (2018). Research design: Qualitative, quantitative, and mixed methods approaches (5 ${ }^{\text {th }}$ ed.). Los Angeles, CA: SAGE publications.

Dickson, L., Brown, M., \& Gibson, O. (1984). Children learn mathematics: A teacher's guide to recent research. London, Great Britain: Holt, Rinehart and Winston Ltd.

Dorko, A., \& Speer, N. (2015). Calculus students' understanding of area and volume units. Investigations in Mathematics Learning, 8(1), 23-46. https:/ / doi.org/10.1080/24727466.2015.11790346

Goldin, G. A. (2003). Representation in school mathematics: A unifying research perspective. In J. Kilpatrick, W. G. Martin, \& D. Schifter (Eds.), A research companion to principles and standards for school mathematics (pp. 275285). Reston, VA: National Council of Teachers of Mathematics. 
Guven, B. (2012). Using dynamic geometry software to improve eight grade students' understanding of transformation geometry. Australasian Journal of Educational Technology, 28(2), 364-382. https://doi.org/10.14742/ajet.878

Hawes, Z., Moss, J., Caswell, B., Naqvi, S., \& MacKinnon, S. (2017). Enhancing children's spatial and numerical skills through a dynamic spatial approach to early geometry instruction: Effects of a 32-week intervention. Cognition and Instruction, 35(3), 236-264. https:/ / doi.org/10.1080/07370008.2017.1323902

Henningsen, M., \& Stein, M. K. (1997). Mathematical tasks and student cognition: Classroom-based factors that support and inhibit high-level mathematical thinking and reasoning Journal for Research in Mathematics Education, 28(5), 524-549. https:/ / doi.org/10.2307/749690

Hiebert, J., \& Carpenter, T. P. (1992). Learning and teaching with understanding. In D. A. Grouws (Ed.), Handbook of research on mathematics teaching and learning (pp. 65-97). New York, NY: Macmillan.

Hsieh, M.-H., \& Huang, H.-M. E. (2013). The influence of digital materials for teaching volume measurement on fourth-graders' learning of volume concepts. In National Academy for Educational Research (Ed.), Conference handbook of 2013 Trend of Development of Digital Textbooks for Elementary and Junior-High Schools, pp. 91-99. (In Chinese.) Taipei, Taiwan: Taipei Branch of National Academy for Educational Research.

Huang, H.-M. E. (2015a). Elementary-school teachers' instruction in measurement: Cases of classroom teaching of spatial measure in Taiwan. In L. Fan, N.Y. Wong, J. Cai, \& S.-Q. Li (Eds.), How Chinese teach mathematics: Perspectives from insiders, pp. 149-184. Singapore: World Scientific Publishing Co.

Huang, H.-M. E. (2015b). An experiment of three-dimensional spatial geometry and volume measurement integrated digital teaching materials and instruction. Chinese Journal of Science Education, 23(1), 53-82. (In Chinese.) https:/ / doi.org/10.6173/CJSE.2015.2301.03

Huang, H.-M. E. (2017). Curriculum interventions for area measurement instruction to enhance children's conceptual understanding. International Journal of Science and Mathematics Education, 15(7), 1323-1341. https:/ / doi.org/10.1007/s10763-016-9745-7

Kerslake, D. (1976). Volume and capacity. Mathematics Teaching, 77, 14-15.

Lehrer, R. (2003). Developing understanding of measurement. In J. Kilpatrick, W. G. Martin, \& D. Schifter (Eds.), A research companion to principles and standards for school mathematics (pp. 179-192). Reston, VA: National Council of Teachers of Mathematics.

Ministry of Education (2010). Grade 1-9 curriculum guidelines. Mathematics filed. (In Chinese) Taipei, Taiwan: Author.

National Council of Teachers of Mathematics (2006). Curriculum focal points for prekindergarten through grade 8 mathematics. Reston, VA: Author.

Novick, L. R., \& Hmelo, C. E. (1994). Transferring symbolic representations across nonisomorphic problems. Journal of Experimental Psychology: Learning, Memory, and Cognition, 20(6), 1296-1321. https://doi.org/10.1037/02787393.20.6.1296

Resnick, L. B. (2010). 2009 Wallace Foundation distinguished lecture: nested learning systems for the thinking curriculum Educational Researcher, 39(3), 183-197. https:/ / doi.org/10.3102/0013189X10364671

Seufert, T. (2003). Supporting coherence formation in learning from multiple representations. Learning and Instruction, 13, 227-237. https:// doi.org/10.1016/S0959-4752(02)00022-1

Shaffer, D. W., \& Kaput, J. J. (1999). Mathematics and virtual cultural: An evolutionary perspective technology and mathematics education Educational Studies in Mathematics, 37, 97-119. https://doi.org/10.1023/A:1003590914788

Simon, M. A. (1996). Beyond inductive and deductive reasoning: The search for a sense of knowing. Educational Studies in Mathematics, 30, 197-210. https:/ / doi.org/10.1007/BF00302630

Tan, N.-J. (1998). A study on the students' misconceptions of area in the elementary school. (In Chinese.) Journal of National Taipei Teachers College, XI, 573-602.

The University of Chicago School Mathematics Project (2012). Everyday mathematics: Teacher's lesson guide (Grade 5) (3rd ed., Vol. 2). Chicago, IL: The McGraw-Hill companies.

Van de Walle, J. A., Karp, K. S., \& Bay-Williams, J. M. (2012). Elementary and middle school mathematics: Teaching developmentally (8th ed.). New York, NY: Pearson.

Vasilyeva, M., Ganley, C. M., Casey, B. M., Dulaney, A., Tillinger, M., \& Anderson, K. (2013). How children determine the size of 3D structures: Investigating factors influencing strategy choice. Cognition and Instruction, 31(1), 29-61. https:/ / doi.org/10.1080/07370008.2012.742086 


\section{APPENDIX I}

Examples of Teaching Manuals of Geometric Knowledge and Volume Measurement (GKVM) Curriculum and Volume Measurement (VM) Curriculum in the Phase 1 Study

\section{Example of the Teaching manuals of GKVM curriculum}

\section{Q16-2. If you were to express the volume of this rectangular solid with a formula} that includes the multiplication symbol " $\times$ ", how would you express it?
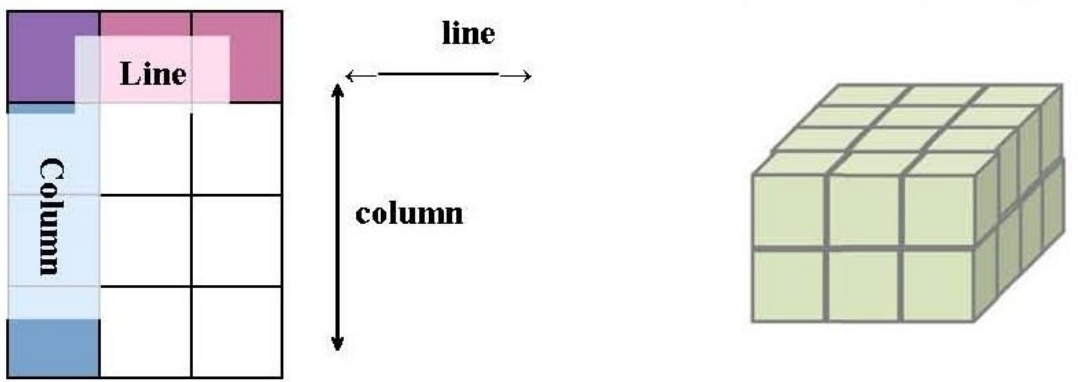

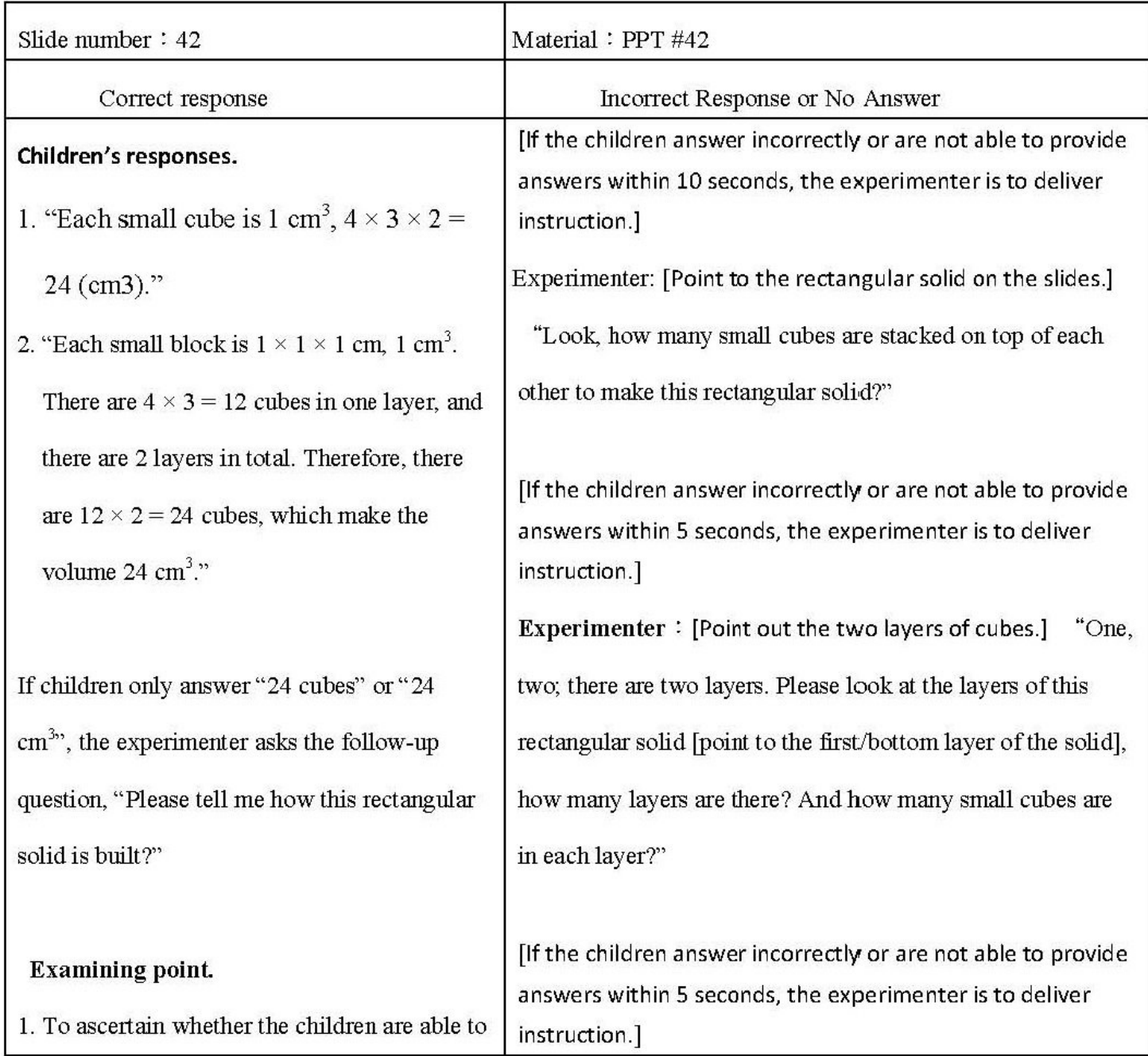


conclude that the rectangular solid is constructed of multiple units of smaller cubes (of the same volume) after observing the way that the small cubes are stacked.

2. To confirm that the children are able to observe and explain that the base of a layer is a 2-dimensional rectangular face.

Multiples of the identical rectangular layer, with the area of its base of $2 \mathrm{~cm}^{2}$ and $1 \mathrm{~cm}$ in height, can be stacked on top of each other, and a rectangular solid is formed. The length and width of this rectangular solid should be the same as that of the length and width of the base, a rectangular

2-dimensional face. The height is formed after stacking multiples of identical layers, which results in a 3 dimensional rectangular solid.

3. To confirm that the children are able to observe and express "the volume of a rectangular solid is given by the area of base (length $\times$ width) multiplied by height."
Experimenter : [Point to the top 3 layers of cubes.] "The top layer of this rectangular solid is constructed by $1,2,3$, three layers of small cubes. Every layer has 1, 2, 3, 4, four small cubes. So, [point to the top layer] how many small cubes are in this layer?"

[If the children answer incorrectly or are not able to provide answers within 5 seconds, the experimenter is to deliver instruction.]

Experimenter : [Point out every layer.] "Look, this layer has 3 columns, each column is made up of 4 small cubes.

Therefore, in each layer there are $4+4+4=12,12$ cubes. How many layers are in the rectangular solid? How many cubes make up the length, width and height of this rectangular solid?"

[If the children answer incorrectly or are not able to provide answers within 5 seconds, the experimenter is to deliver instruction.]

Experimenter: "This solid has two layers, which means that its height [point to the vertical side] is made up of two cubes. The length side and width side are composed of 4 and 3 small cubes. This means that this face [point to the surface of first layer] has 3 columns and each column has 4 small cubes. Therefore, the length and width of this solid are $4 \mathrm{~cm}$ and 3 $\mathrm{cm}$ [point out the length and width sides]. This makes it a rectangular solid.

Take a look at the second layer of this solid [point out the second layer], how many cubes are used to make up this 
layer?"

[If the children answer incorrectly or are not able to provide answers within 5 seconds, the experimenter is to deliver instruction.]

Experimenter: "The second layer is also $4 \times 3=12$, composed of 12 small cubes. We just counted 2 layers of cubes, each layer has 12 small cubes. So, [point out the two layers] how many small cubes are there in total?)

[If the children answer incorrectly or are not able to provide answers within 5 seconds, the experimenter is to deliver instruction.]

Experimenter: "Every layer has 12 small cubes. This can be calculated $12+12=24,24$ cubes in total are in the two layers. We may also use multiplication to calculate the number of cubes, $12 \times 2=24$, there are 24 cubes. If the volume of each of these small cubes is $1 \mathrm{~cm}^{3}$, what is the volume of this rectangular solid?"

[If the children answer incorrectly or are not able to provide answers within 5 seconds, the experimenter is to deliver instruction.]

Experimenter: 'Each small cube is $1 \mathrm{~cm}^{3}$; the two layers of cubes consist of 24 units of $1 \mathrm{~cm}^{3}$. Therefore, [point to the rectangular solid] the volume of this rectangular solid is (1 $\left.\mathrm{cm}^{3} \times 24\right) 24 \mathrm{~cm}^{3}$. This means that the base of this rectangular solid is a $4 \mathrm{~cm} \times 3 \mathrm{~cm}$ rectangle, the height is a layer is $1 \mathrm{~cm}$. Thus, the volume of a layer is $1 \mathrm{~cm} \times 4 \mathrm{~cm} \times 3 \mathrm{~cm}, 12 \mathrm{~cm}^{3}$. Multiples of these identical rectangular layers stacked on top 
of each other give the volume of the rectangular solid. This rectangular solid has the same length and width as those of the rectangle base, while the height, $2 \mathrm{~cm}$, is the result of stacking two layers. Therefore, the volume of a layer of the rectangle solid is $4 \mathrm{~cm} \times 3 \mathrm{~cm} \times 1 \mathrm{~cm}$. Since there are 2 layers in the rectangular solid, the total volume of the rectangular solid is $4 \mathrm{~cm} \times 3 \mathrm{~cm} \times 2 \mathrm{~cm}$.

We can also calculate the area of the base of the rectangular solid. The area of the base is $4 \mathrm{~cm} \times 3 \mathrm{~cm}=12\left(\mathrm{~cm}^{2}\right)$, while the height of the solid is $2 \mathrm{~cm}$. The volume of the rectangular solid is $12 \times 2=24\left(\mathrm{~cm}^{3}\right)$. That is, the product of the area of the base times height gives the volume of this rectangular solid." 


\section{Example of the Teaching manuals of VM curriculum}

Q14-3. We now know the number of cubes in one layer of this rectangular solid.

How many cubes are used to construct all 3 layers? How do you know?

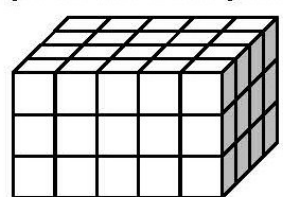

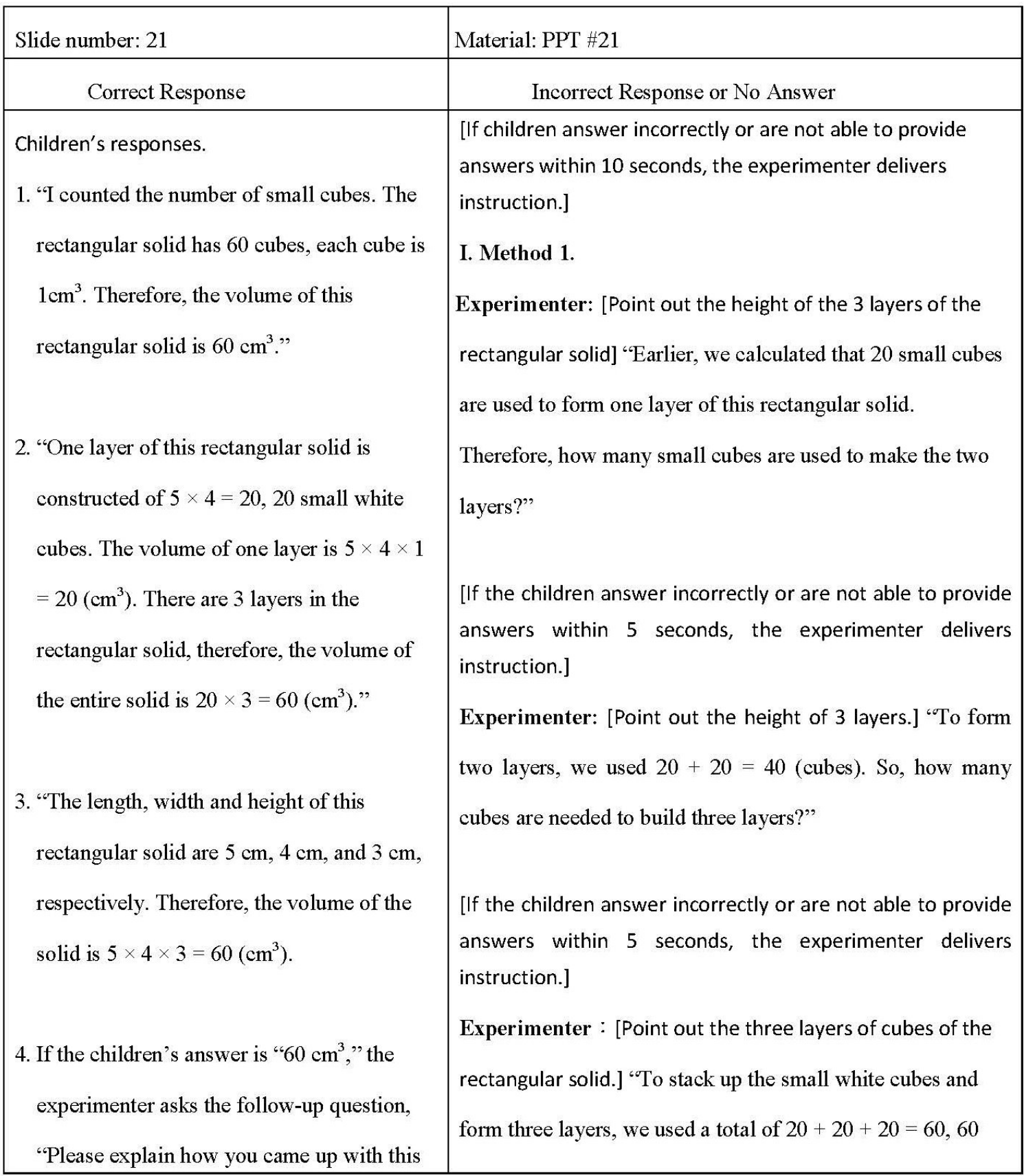


answer."
Examining point.
1. To confirm that the children are able to
measure the volume of rectangular solids
and understand the concept of volume
measurement of rectangular solids; that they
are able to calculate the volume of a
rectangular solid by multiplying (stacking)

identical cubic units (layers), and then

calculate the total volume in terms of the number of cubic units.

2. To confirm that the children are able to identify and measure the length, width and height; and that he/she is able to measure and calculate the volume of a rectangular solid. cubes."

\section{Method 2.}

Experimenter: [Point out the top layer of the rectangular solid.] "This rectangular solid is composed of 3 layers of small cubes. Earlier we calculated that there are 20 small cubes in one layer, as it has 5 cubes on its length side and 4 cubes on its width side. To calculate the total number of cubes in a layer is $5 \times 4=20$ (cubes). So, how many small white cubes in total are needed for 3 layers?"

[If the children answer incorrectly or are not able to provide answers within 5 seconds, the experimenter delivers instruction.]

Experimenter: [Point out the 3 layers of the rectangular solid.] "Earlier we calculated that each layer has $5 \times 4=$ 20 (cubes); therefore, for calculating the three layers, $5 \times 4 \times$ $3=60$. There are 60 small white cubes in total used to make all three layers of this rectangular solid." 


\section{APPENDIX II}

\section{The Pre-test and Post-test Used in the Phase 1 Study}

\section{The pre-test used in the Phase 1 study}

1. Ann wants to know the meaning of "volume." Can you explain it to her? Please write down your ideas.

2. Solids A and B are constructed with 1- $\mathrm{cm}^{3}$ cubes. Please answer the questions according to the figures below.
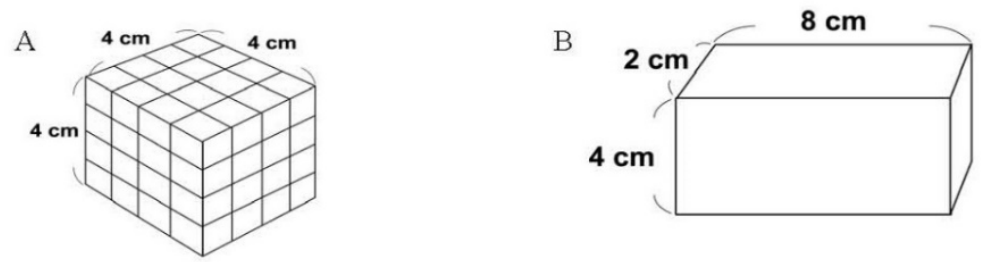

Joey says, "The volume of A is the same as the volume of B." Do you agree with him? Why or why not? Please write down your ideas.

3. Solid A is filled with 4 layers of cubes. Ms. Wang placed this solid on a grid board. Please answer the questions below according to the figure.

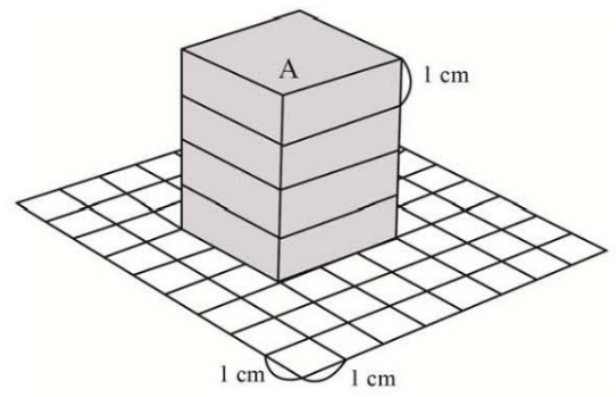

(1) What is the volume of one layer in cubic centimeters? Please use arithmetic operations to express your ideas.

(2) What is the volume of solid A in cubic centimeters? Please use arithmetic operations to express your ideas.

4. This is a $1-\mathrm{cm}^{3}$ cube. The figure below is a rectangular box that is partially filled with $1-\mathrm{cm}^{3}$ cubes. Please answer the following questions.

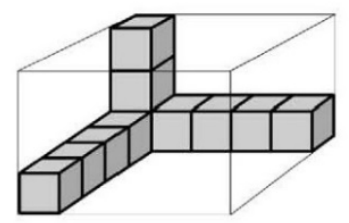

(1) Jackson says, "The area of the base of the rectangular box is $4 \times 4=16\left(\mathrm{~cm}^{2}\right)$ and the height is $2 \mathrm{~cm}$." Do you agree with him? Why or why not? Please write down your ideas

(2) Ms. Wang uses to completely fill the rectangular box. How many cubes in total are needed? Please use arithmetic operations to express your ideas 
5. Chi used $201-\mathrm{cm}^{3}$ cubes to make a rectangular solid. Chi says, "The width of the rectangular solid is $2 \mathrm{~cm}$ and the height is $2 \mathrm{~cm} . "$

(1) Do you know the length of the rectangular solid in centimeters?

Please use arithmetic operations to express your ideas.

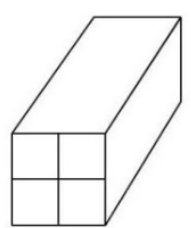

(2) Lily says, "The volume of Chi's rectangular solid is $4 \mathrm{~cm}^{3}$ because the volume is $2 \times 2=4\left(\mathrm{~cm}^{3}\right)$."

Do you agree with her? Why or why not? Please write down your ideas.

6-1. Mr. Lee wants to lay a carpet on the floor of his storage room. In order to buy a carpet that best fits his floor, what should he measure?

( ) (1) What measurement would you suggest for Mr. Lee?

(1) estimate the volume of the carpet; (2) volume; (3) angle; (4) area; (5) weight).

(2) Please write down your ideas about what he should measure.

6-2. Mr. Lee wants to place a big cardboard box in the storage room. In order to make sure that the cardboard box can fit into the storage room, what should he measure?

( ) (1) What measurement would you suggest for Mr. Lee?

(1) weight; (2) volume; (3) angle; (4) area; (5) estimate the total surface area of the cardboard box).

(2) Please write down your ideas about what he should measure.

7. Luke says, "Solid A looks different from solid B. The volumes of solids A and B are different, too."

Do you agree with him? Why or why not? Please write down your ideas.

A.

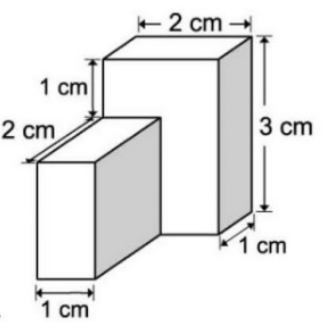

B.

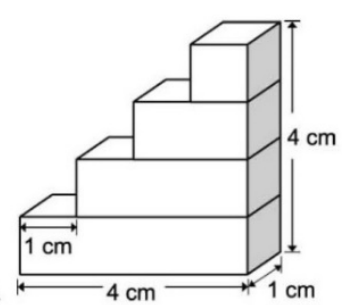




\section{The post-test used in the Phase 1 study}

1. Do you know the meaning of "volume"? Please write down your ideas.

2. Solids A and B are filled with $1-\mathrm{cm}^{3}$ cubes. Please answer questions according to the figures below.

A

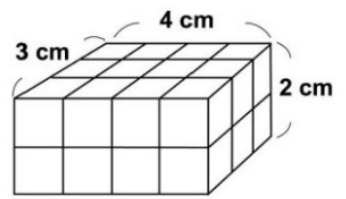

B

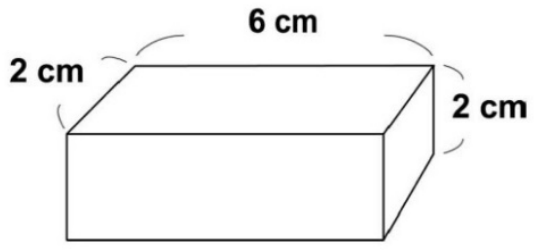

Joe says, "The volume of solid A is the same as the volume of solid B." Do you agree with him? Why or why not? Please write down your ideas.

3. Solid A is filled with 3 layers of cubes. Ms. Wang placed this solid on a grid board. Please answer the questions below according to the figure.

(1) What is the volume of one layer in cubic centimeters? Please use arithmetic operations to express your ideas.

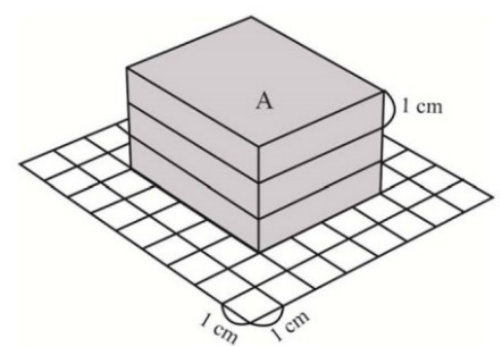

(2) What is the total volume of solid A in cubic centimeters? Please use arithmetic operations to express your ideas.

4 .

This is a $1-\mathrm{cm}^{3}$ cube. The figure below is a rectangular box that is partially filled with $1-\mathrm{cm}^{3}$ cubes. Please answer the following questions.

(1) Tom says, "The area of the base of the rectangular box is $3 \times 3=9\left(\mathrm{~cm}^{2}\right)$ and the height is $3 \mathrm{~cm}$." Do you agree with him? Why or why not? Please write down your ideas.

(2) Do you know how many in total are needed for Tom to completely fill the rectangular box? Please use arithmetic operations to express your ideas.

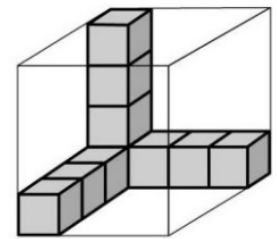


5. Chi used $361-\mathrm{cm}^{3}$ cubes to make a rectangular solid. He says, "The width of the rectangular solid is $3 \mathrm{~cm}$ and the height is $2 \mathrm{~cm}$."

(1)Do you know how long the rectangular solid is in centimeters?

Please use arithmetic operations to express your ideas.

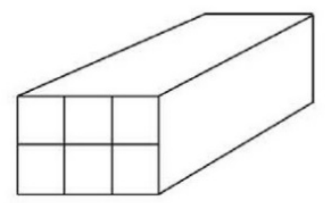

(2)Lily says, "The volume of Chi's rectangular solid stacked is $6 \mathrm{~cm}^{3}$ because the volume is $3 \times 2=6\left(\mathrm{~cm}^{3}\right)$."

Do you agree with her? Why or why not? Please write down your ideas.

6-1. Mrs. Lee wants to cover the base of a cupboard with a plastic mat. In order to buy a mat that best fits the space of the base of the cupboard, what should she measure?

( ) (1) What measurement would you suggest for Mrs. Lee? (1) estimate the volume of the mat; (2) volume; (3) angle; (4) area; (5) weight).

(2) Please write down your ideas about what to measure.

6-2. Mrs. Lee wants to put a microwave into the cupboard. In order to make sure that the microwave can fit into the cupboard, what should she measure?

( ) (1) What measurement would you suggest for Mrs. Lee?

(1) weight; (2) volume; (3) angle; (4) area; (5) estimate the total surface area of the microwave).

(2) Please write down your ideas about what to measure.

7. Allen says, "Solid A looks different from solid B. The volumes of solids A and B are different, too." Do you agree with him? Why or why not? Please write down your ideas.

A.

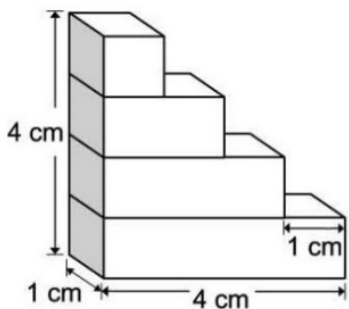

B.

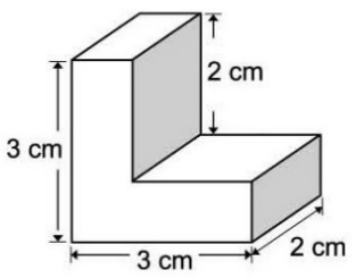


1. Ann wants to know the meaning of "volume." Can you explain it to her? Please write down your ideas.

2. Solids $\mathrm{A}$ and $\mathrm{B}$ are constructed with $1-\mathrm{cm}^{3}$ cubes. Please answer the questions according to the figures below.
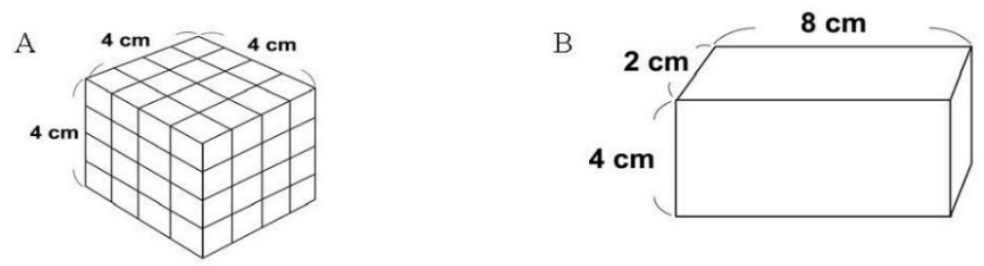

Joey says, "The volume of A is the same as the volume of B." Do you agree with him? Why or why not? Please write down your ideas.

3. Solid A is filled with 4 layers of cubes. Ms. Wang placed this solid on a grid board. Please answer the questions below according to the figure

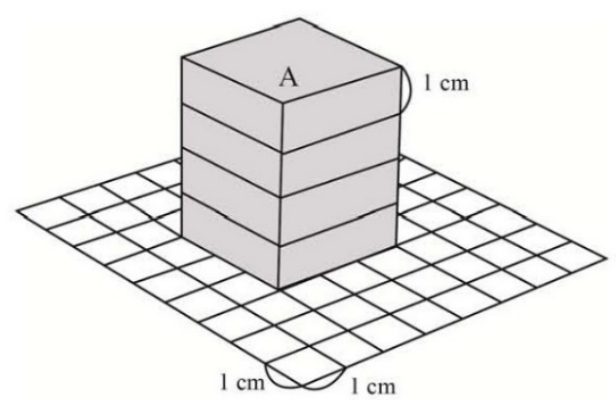

(1) What is the volume of one layer in cubic centimeters? Please use arithmetic operations to express your ideas.

(2) What is the volume of solid A in cubic centimeters? Please use arithmetic operations to express your ideas.

4. This is a $1-\mathrm{cm}^{3}$ cube. The figure below is a rectangular box that is partially filled with $1-\mathrm{cm}^{3}$ cubes. Please answer the following questions.

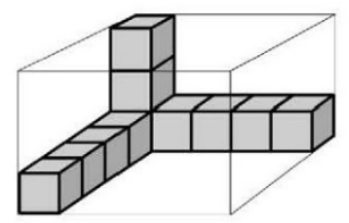

(1) Jackson says, "The area of the base of the rectangular box is $4 \times 4=16\left(\mathrm{~cm}^{2}\right)$ and the height is $2 \mathrm{~cm} . "$

Do you agree with him? Why or why not? Please write down your ideas

(2) Ms. Wang uses to completely fill the rectangular box. How many cubes in total are needed? Please use arithmetic operations to express your ideas 
Problem type and numbers of items used in the pretest and post-test in the Phase 1 study

Table 1. Problem type and numbers of items used in the pretest and post-test in Phase 1

\begin{tabular}{|c|c|c|c|c|c|c|c|c|}
\hline \multirow[t]{2}{*}{$\begin{array}{l}\text { Problem type } \\
\text { and item }\end{array}$} & \multicolumn{2}{|c|}{$\begin{array}{l}\text { Numerical volume } \\
\text { calculation (NVC) }\end{array}$} & \multicolumn{2}{|c|}{$\begin{array}{c}\text { Mathematical judgement and } \\
\text { explanation (MJ-EXP) }\end{array}$} & \multicolumn{2}{|c|}{ Short answer (SA) } & \multicolumn{2}{|c|}{$\begin{array}{c}\text { Multiple choice and short } \\
\text { answer (MC-SA) }\end{array}$} \\
\hline & Pre-test & Post-test & Pre-test & Post-test & Pre-test & Post-test & Pre-test & Post-test \\
\hline \multirow[t]{4}{*}{ Item } & $3-(1) 3-(2)$ & $3-(1) 3-(2)$ & 2 & 2 & 1 & 1 & $6-1$ & $6-1$ \\
\hline & $4-(2)$ & $4-(2)$ & $4-(1)$ & $4-(1)$ & & & $6-2$ & $6-2$ \\
\hline & $5-(1)$ & $5-(1)$ & $5-(2)$ & $5-(2)$ & & & & \\
\hline & & & 7 & 7 & & & & \\
\hline Total & 4 & 4 & $4_{1}$ & $44_{1}$ & 1 & 1 & 22 & 22 \\
\hline
\end{tabular}




\section{APPENDIX III}

\section{The Pre-test and Post-test Used in the Phase 2 Study}

\section{The pre-test used in the Phase 2 study}

1. Do you know the meaning of "volume"? Please write down your thoughts.

2. This is a $1-\mathrm{cm}^{3}$ cube. The figure below is a rectangular box that is partially filled with $1-\mathrm{cm}^{3}$ cubes. Wei completely fills the rectangular box with the cubes

(1) Wei wholly submerges the rectangular box completely filled with the $1-\mathrm{cm}^{3}$ cubes into a container completely full of water. What is the volume of water pushed out of the container?

Please use arithmetic operations to express your ideas.

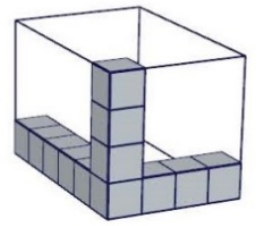

(2) Wei wholly submerges the rectangular box completely filled with the $1-\mathrm{cm}^{3}$ cubes into a measuring glass filled with 120 milliliters of water. What is the new level of water in the measuring glass?

Please use arithmetic operations to express your ideas.

3. Ms. Lin has a rectangular aquarium; the interior of the aquarium is $30 \mathrm{~cm}$ long, $30 \mathrm{~cm}$ wide, and $40 \mathrm{~cm}$ high. Please use arithmetic operations to answer the following questions.

(1) Ms. Lin fills the aquarium with water and the water level is at a height of $20 \mathrm{~cm}$. How many milliliters of water are in the aquarium?

(2) Ms. Lin submerges some pebbles into the aquarium, and the water level rises from $20 \mathrm{~cm}$ to $30 \mathrm{~cm}$. What is the total volume of the pebbles?

(3) Ms. Lin wants to completely fill the aquarium with water. What is the capacity of the aquarium?

4. Containers A, B, and C are all made of wooden boards of 1-cm thickness. Ms. Lee measured the interior and exterior sides of each container. Please explain your ideas for the following questions.

(1) A is a lidless container with interior length, width, and height of $30 \mathrm{~cm}$ each. $\mathrm{B}$ is a container with a lid with exterior length, width, and height of $30 \mathrm{~cm}$ each. Which container has a larger volume, A or B? Why?

(2) $\mathrm{A}$ is a lidless container with interior length, width, and height of $30 \mathrm{~cm}$ each. $\mathrm{C}$ is a lidless container with exterior length, width, and height of $30 \mathrm{~cm}$ each. Ms. Lee wants to put $1-\mathrm{cm}^{3}$ cubes into the containers. Which container, A or C, holds more cubes? Why?

(3) B is a container with a lid with exterior length, width, and height of $30 \mathrm{~cm}$ each. $\mathrm{C}$ is a lidless container with exterior length, width, and height of $30 \mathrm{~cm}$ each.

Ming said "The capacity of B and C are the same." Do you agree with him? Why or why not? 
5. Figure $\mathrm{A}$ is a rectangular prism, whereas figure $\mathrm{B}$ is a parallelepiped prism with parallelogram bases. Please answer the questions.

A.

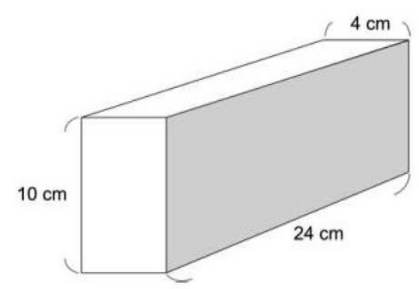

B.

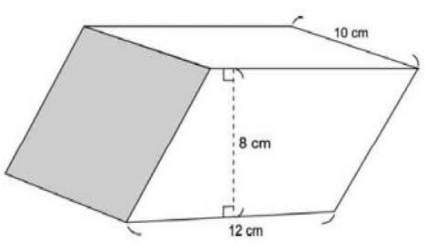

(1) Yu said, "The volume of A looks larger than the volume of B." Do you agree with him? Why or why not? Please write down your ideas.

(2) A is fully submerged into a measuring tank completely filled with water. How many milliliters of the water are pushed out of the tank?

6. Triangular prism A is made of 4 layers of small triangular prisms. Ms. Wang places prism A on a piece of 1-cm grid board. Please answer the following questions.

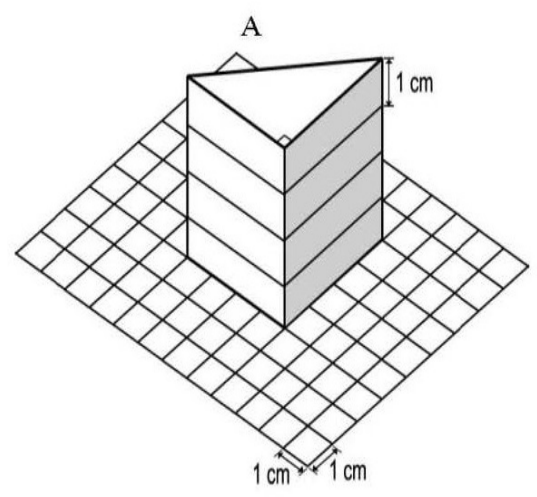

(1) What is the volume of one layer in cubic centimeters? Please use arithmetic operations to express your ideas.

(2) What is the total volume of prism A in cubic centimeters? Please use arithmetic operations to express your ideas.

(3) If prism A is fully submerged into a measuring cup completely filled with water, how many milliliters of water are pushed out of the measuring cup? Please write down your answer or ideas.

(4) The length, width and height of rectangular prism B are $2 \mathrm{~cm}, 8 \mathrm{~cm}$, and $2 \mathrm{~cm}$, respectively. Ms. Wang submerges prisms A and B into separate identical measuring cups that both contain 80 milliliters of water. She then observed the new levels of water in each measuring cup.

Lily said, "The water in both of the measuring cups rises by the same amount." Do you agree with her? Why or why not? Please write down your ideas. 


\section{The post-test used in the Phase 2 study}

1. Do you know the meaning of "volume"? Please write down your ideas.

2.

This is a $1-\mathrm{cm}^{3}$ cube. The figure below is a rectangular box that is partially filled with $1-\mathrm{cm}^{3}$ cubes. Wei completely fills the rectangular box with the cubes

(1) Wei wholly submerges the rectangular box completely filled with the $1-\mathrm{cm}^{3}$ cubes into a container full of water. What is the volume of water pushed out of the container?

Please use arithmetic operations to express your ideas.

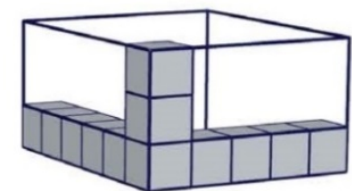

(2) Joey wholly submerges the rectangular box completely filled with the $1-\mathrm{cm}^{3}$ cubes into a measuring glass with 120 milliliters of water. What is the new level of water in the measuring glass? Please use arithmetic operations to express your ideas.

3. Mr. Jackson has a rectangular aquarium; the interior of the aquarium is $30 \mathrm{~cm}$ long, $20 \mathrm{~cm}$ wide and $40 \mathrm{~cm}$ high. Please use arithmetic operations to answer the following questions

(1) Mr. Jackson fills the aquarium with water and the water level is at $20 \mathrm{~cm}$ high. How many milliliters of water are in the aquarium?

(2) Mr. Jackson places some pebbles into the aquarium, and the water level rises from $20 \mathrm{~cm}$ to $30 \mathrm{~cm}$. What is the total volume of the pebbles?

(3) Mr. Jackson wants to completely fill the aquarium with water. What is the capacity of the aquarium?

4. Containers A, B, and C are made of wooden boards of 1-cm thickness. Mr. Lee measures the interior and exterior sides of each box. Please explain your ideas for the questions below.

(1) A is a lidless box with interior length, width, and height of $40 \mathrm{~cm}$ each. B is a box with a lid with exterior length, width, and height of $40 \mathrm{~cm}$ each. Which container has a larger volume, $\mathrm{A}$ or $\mathrm{B}$ ? Why?

(2) A is a lidless box with interior length, width, and height of $40 \mathrm{~cm}$ each. $\mathrm{C}$ is a lidless box with exterior length, width, and height of $40 \mathrm{~cm}$ each. Mr. Lee wants to completely fill the containers with $1-\mathrm{cm}^{3}$ cubes. Which container holds more cubes, A or C? Why?

(3) $\mathrm{B}$ is a container with a lid with exterior length, width, and height of $40 \mathrm{~cm}$ each. $\mathrm{C}$ is a lidless box with exterior length, width, and height of $40 \mathrm{~cm}$ each.

Micah says, "The capacity of B and C are the same." Do you agree with him? Why or why not? 
5. Figure $\mathrm{A}$ is a rectangular prism. Figure $\mathrm{B}$ is a parallelepiped prism with parallelogram bases. Please answer the questions.

A.

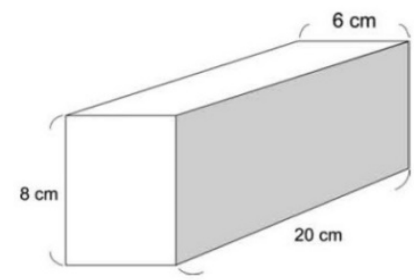

B.

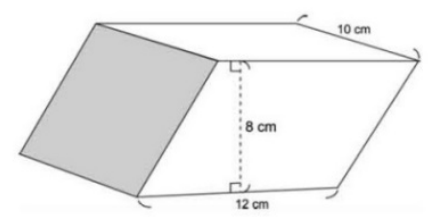

(1) Joey says, "The volume of B looks larger than the volume of A." Do you agree with him? Why or why not? Please write down your ideas.

(2) A is fully submerged into a measuring tank completely filled with water. How many milliliters of water are pushed out of the tank?

6. Triangular prism A is made of 4 layers of small triangular prisms. Ms. Wang places prism A on a piece of 1-cm grid board. Please answer the following questions.

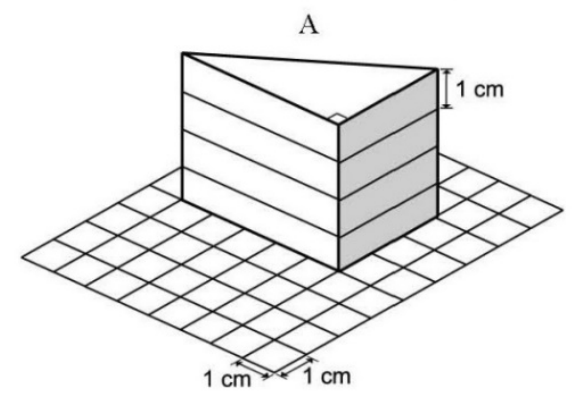

(1) What is the volume of one layer in cubic centimeters?

Please use arithmetic operations to express your ideas.

(2) What is the total volume of prism A in cubic centimeters? Please use arithmetic operations to express your ideas.

(3) If prism A is fully submerged into a measuring cup completely filled with water, how many milliliters of water are pushed out of the measuring cup? Please write down your answer or ideas.

(4) The length, width and height of rectangular prism $B$ are $2 \mathrm{~cm}, 10 \mathrm{~cm}$, and $3 \mathrm{~cm}$, respectively. Ms. Wang submerges prisms A and B into separate identical measuring cups that both contain 80 milliliters of water. She then observed the new levels of water in each measuring cup.

Ginny said, "The water levels in both of the measuring cups rise by the same amount." Do you agree with her? Why or why not? Please write down your ideas. 
Problem type and numbers of items used in the pretest and post-test in the Phase 2 study

Table 2. Problem type and numbers of items used in the pretest and post-test in Phase 2

\begin{tabular}{|c|c|c|c|c|c|c|c|c|}
\hline \multirow[t]{2}{*}{$\begin{array}{l}\text { Problem type } \\
\text { and item }\end{array}$} & \multicolumn{2}{|c|}{$\begin{array}{l}\text { Numerical volume } \\
\text { calculation (NVC) }\end{array}$} & \multicolumn{2}{|c|}{$\begin{array}{c}\text { Mathematical judgement and } \\
\text { explanation (MJ-EXP) }\end{array}$} & \multicolumn{2}{|c|}{ Short answer (SA) } & \multicolumn{2}{|c|}{$\begin{array}{c}\text { SA and explanation } \\
\text { (SA-EXP) }\end{array}$} \\
\hline & Pre-test & Post-test & Pre-test & Post-test & Pre-test & Post-test & Pre-test & Post-test \\
\hline \multirow[t]{8}{*}{ Item } & $2-(1)$ & $2-(1) 2-(2)$ & $4-(3)$ & $4-(3)$ & 1 & 1 & $4-(1)$ & $4-(1)$ \\
\hline & $2-(2)$ & $3-(1) 3-(2)$ & $5-(1)$ & $5-(1)$ & & & $4-(2)$ & $4-(2)$ \\
\hline & $3-(1)$ & $4-(2)$ & $6-(4)$ & $6-(4)$ & & & $6-(3)$ & $6-(3)$ \\
\hline & $3-(2)$ & $5-(2)$ & & & & & & \\
\hline & $3-(3)$ & $6-(1)$ & & & & & & \\
\hline & $5-(2)$ & $6-(2)$ & & & & & & \\
\hline & $6-(1)$ & & & & & & & \\
\hline & 6-(2) & & & & & & & \\
\hline Total & 8 & 8 & $3_{1}$ & $3_{1}$ & 1 & 1 & $3_{2}$ & $3_{2}$ \\
\hline
\end{tabular}

Note.

1. The footnote number, 1 , represents a mathematical judgement and explanation item pair.

2. The footnote number, 2 , represents a SA and explanation item pair. 


\section{APPENDIX IV}

\section{Reasons Responded by the Interviewees' of the GKVM and VM Groups in the Phase 2 Study}

Table 1. Reasons responded by the interviewees of the GKVM group $(n=15)$

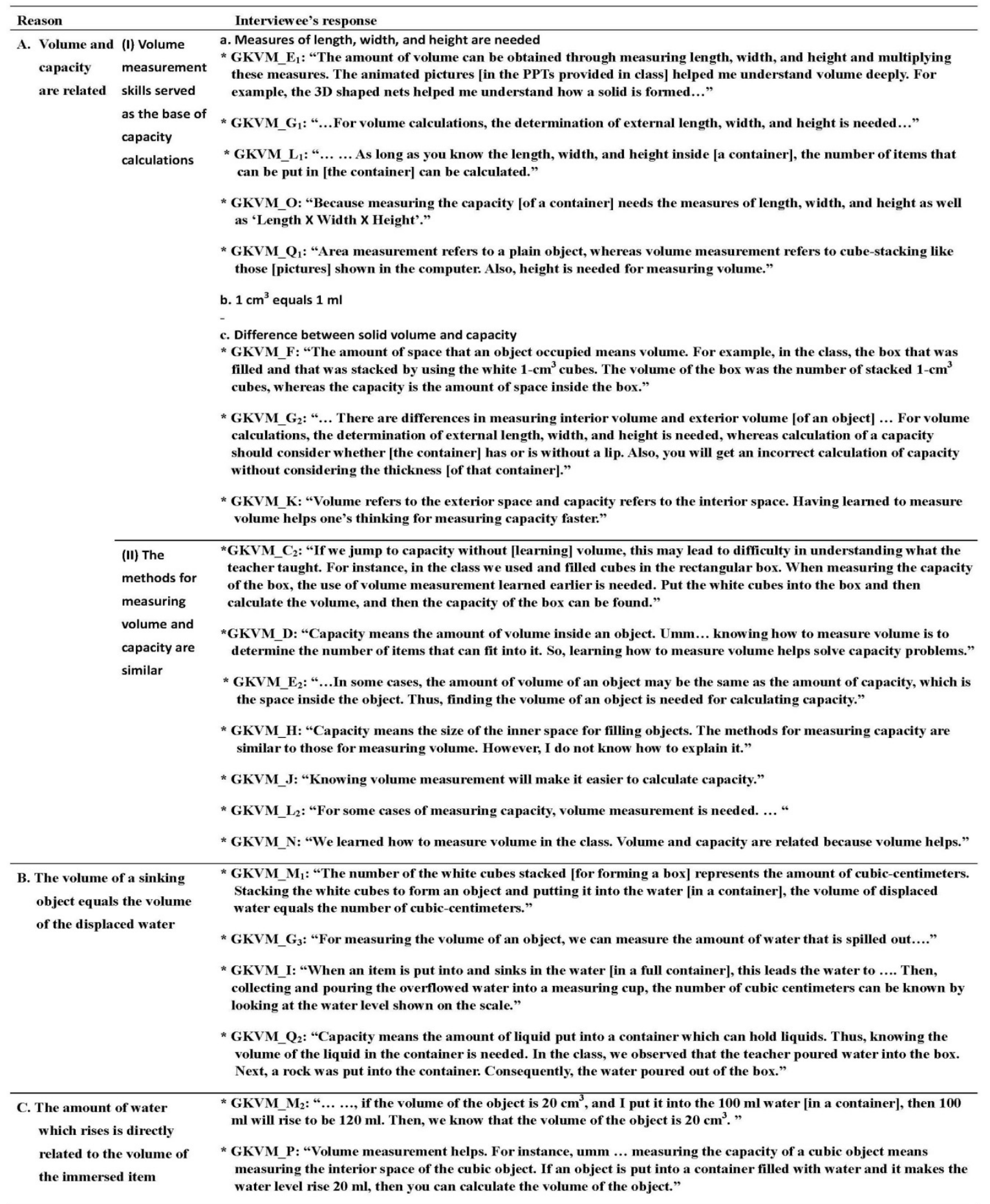

Note.

1. GKVM = geometry and volume measurement instructional treatment. The alphabet after GKVM represents the code of one interviewee.

2. The footnote numbers (e.g., 1,2, and ${ }_{3}$ ) represent the frequency of a description indicated by one interviewee who stated that more than one viewpoint was categorized. 
Table 2. Reasons responded by the interviewees of the VM group $(n=14)$

\begin{tabular}{|c|c|c|}
\hline \multicolumn{2}{|c|}{ Reason } & Interviewee's responses \\
\hline \multirow[t]{9}{*}{$\begin{array}{l}\text { A. Volume } \\
\text { and } \\
\text { capacity } \\
\text { are related }\end{array}$} & $\begin{array}{l}\text { (I) Volume } \\
\text { measurement } \\
\text { skills served as } \\
\text { the base of } \\
\text { capacity }\end{array}$ & $\begin{array}{l}\text { a. Measures of length, width, and height are needed } \\
\text { *VM_N: "There are some similarities between measuring volume and capacity. You calculate the volume of a liquid, a } \\
\text { liquid, that is, you pour the liquid into a cubic box of which the length, width, and height are there. Volume } \\
\text { measurement let me know the amount of liquid in the container: After the liquid is put [in the container], the length, } \\
\text { width, and height of the liquid are presented [from the container]. Then, you can find the volume of the liquid in the } \\
\text { container:" }\end{array}$ \\
\hline & calculations & $\begin{array}{l}\text { b. } 1 \mathrm{~cm}^{3} \text { equals } 1 \mathrm{ml} \\
\text { *VM_B: "As measuring capacity is to measure the inner space of an object and } 1 \text { cubic centimeter equals } 1 \text { milliliter, } \\
\text { finding the volume [of an object] is necessary to know the amount of space inside [the object] that can hold items." }\end{array}$ \\
\hline & & $\begin{array}{l}\text { *VM_E: " } 1 \mathrm{~cm}^{3} \text { equals } 1 \text { milligram", volume measurement is similar to measuring capacity. Both are measuring the } \\
\text { size [of an object] but I am not good at explaining it." }\end{array}$ \\
\hline & & $\begin{array}{l}\text { *VM_F: "Because the teacher taught in the class ' } 1 \text { cubic centimeter equals } 1 \text { millimeter }{ }^{\mathrm{b}}, \text { measuring capacity is } \\
\text { connected with volume measurement. If you did not learn volume measurement first, you would not know how to } \\
\text { calculate capacity." }\end{array}$ \\
\hline & & $\begin{array}{l}\text { *VM_I: "Learning volume measurement will help us know ways to calculate the size of an object, the inner space of } \\
\text { an object. As ' } 1 \mathrm{~cm}^{3} \text { equals } 1 \mathrm{ml} \text {,' calculating the volume [of an object] is also measuring its capacity." }\end{array}$ \\
\hline & & c. Difference between solid volume and capacity \\
\hline & & $\begin{array}{l}\text { * VM_ } J_{1}: \text { "Because measuring capacity is to find the volume inside [a container], I can measure the volume [of the } \\
\text { container] first, and then calculate the volume of the hollow space inside [the container]. Next, you can know what } \\
\text { the capacity [of the container] is, in the end, by means of removing the one with the smaller amount of volume from } \\
\text { the other one with the larger amount of volume." }\end{array}$ \\
\hline & & $\begin{array}{l}\text { *VM_O: "Volume and capacity are related. I think that the general meaning of capacity is about ... umm ... counting } \\
\text { the number of items inside. Volume is the outer [measurement]. There are a few relationships between volume and } \\
\text { capacity. That is, volume measurement counts the outer only, whereas capacity counts the inner." }\end{array}$ \\
\hline & & $\begin{array}{l}\text { *VM_K: "Having learned volume measurement helps us measure capacity. Because volume measurement is } \\
\text { something to do with solid objects, water needs to be poured into something like a solid which has a hollow space } \\
\text { inside and a bottom for holding water. Capacity can be calculated in the same way as measuring volume. Volume } \\
\text { measurement helps measure the capacity of the water-holding box." }\end{array}$ \\
\hline \multirow{2}{*}{\multicolumn{2}{|c|}{$\begin{array}{l}\text { B. The volume of a sinking } \\
\text { object equals the volume of } \\
\text { the displaced water }\end{array}$}} & $\begin{array}{l}\text { *VM_C: "Throw an object into a container [completely filled with water], then water pours out [of the container]. The } \\
\text { volume of the spilt water is the capacity of the object. Capacity means the volume inside a container that can be } \\
\text { filled. If you know how to measure volume, it will be easier to learn things." }\end{array}$ \\
\hline & & $\begin{array}{l}\text { *VM_M } M_{1} \text { " "Learning volume measurement helps us know how much water is displaced by the volume [of an object] } \\
\text { which is thrown into [the container]. Volume is related to capacity. Because water will spill out when we throw a } \\
\text { white cube into a container that is filled with water:" }\end{array}$ \\
\hline \multirow{3}{*}{\multicolumn{2}{|c|}{$\begin{array}{l}\text { C. The water volume which } \\
\text { rises is directly related to the } \\
\text { volume of the immersed item }\end{array}$}} & $\begin{array}{l}\text { * VM_ } \mathrm{H}_{2}: \text { "I threw a } 1-\mathrm{cm}^{3} \text { cube into the water [in a container] and ...like the story about the method that the crow } \\
\text { obtained and drank the water in the bottle." }\end{array}$ \\
\hline & & $\begin{array}{l}\text { *VM_L: "The capacity [of a container] refers to the amount of water that can be held in the container. Because } \\
\text { volume helps us know, know that the water in the container may rise by the same amount of the volume [as that of } \\
\text { the object thrown into the container]. The learnt volume measurement helps us know how to calculate the volume } \\
\text { [of an object], which in turn helps us know the amount of the extra volume [that comes from the object thrown into } \\
\text { it]." }\end{array}$ \\
\hline & & $\begin{array}{l}\text { * } \mathrm{VM} \mathrm{M}_{2} \text { : "For instance, a } 1 \mathrm{~cm}^{3} \text {-cube is thrown into } 100 \text { c.c. of water in a container... the maximum volume that the } \\
\text { container can hold is } 200 \text { c.c. but it has not been fully filled with water. It turns out to be } 101 \text { c.c. after a white cube } \\
\text { is thrown into [the container]." }\end{array}$ \\
\hline
\end{tabular}

Note.

1. $\mathrm{VM}=$ volume measurement instructional treatment. The alphabet after VM represents the code of one interviewee.

2. The footnote numbers (e.g., 1 and 2 ) represent the frequency of a description indicated by one interviewee who stated that more than one viewpoint was categorized.

3. The superscript letters (e.g., milligram ${ }^{a}$ and millimeter $^{b}$ ) represent errors saying the word 'milliliter.'

\section{http://www.ejmste.com}

